\title{
Interventions to reduce post-acute consequences of diarrheal disease in children: a systematic review
}

\author{
Patricia B. Pavlinac ${ }^{1 *}$, Rebecca L. Brander ${ }^{2}$, Hannah E. Atlas ${ }^{1}$, Grace C. John-Stewart ${ }^{1,2,3,4}$, Donna M. Denno ${ }^{1,3,5}$
} and Judd L. Walson ${ }^{1,2,3,4}$

\begin{abstract}
Background: Although acute diarrhea often leads to acute dehydration and electrolyte imbalance, children with diarrhea also suffer long term morbidity, including recurrent or prolonged diarrhea, loss of weight, and linear growth faltering. They are also at increased risk of post-acute mortality. The objective of this systematic review was to identify interventions that address these longer term consequences of diarrhea.
\end{abstract}

Methods: We searched Medline for randomized controlled trials (RCTs) of interventions conducted in low- and middleincome countries, published between 1980 and 2016 that included children under 15 years of age with diarrhea and followup of at least 7 days. Effect measures were summarized by intervention. PRISMA guidelines were followed.

Results: Among 314 otherwise eligible RCTs, 65\% were excluded because follow-up did not extend beyond 7 days. Forty-six trials were included, the majority of which (59\%) were conducted in Southeast Asia (41\% in Bangladesh alone). Most studies were small, 76\% included less than 200 participants. Interventions included: therapeutic zinc alone (28.3\%) or in combination with vitamin A $(4.3 \%)$, high protein diets (19.6\%), probiotics $(10.9 \%)$, lactose free diets (10.9\%), oral rehydration solution (ORS) formulations (8.7\%), dietary supplements (6.5\%), other dietary interventions (6.5\%), and antimicrobials (4.3\%). Prolonged or recurrent diarrhea was the most commonly reported outcome, and was assessed in ORS, probiotic, vitamin A, and zinc trials with no consistent benefit observed. Seven trials evaluated mortality, with follow-up times ranging from 8 days to 2 years. Only a single trial found a mortality benefit (therapeutic zinc). There were mixed results for dietary interventions affecting growth and diarrhea outcomes in the post-acute period.

Conclusion: Despite the significant post-acute mortality and morbidity associated with diarrheal episodes, there is sparse evidence evaluating the effects of interventions to decrease these sequelae. Adequately powered trials with extended follow-up are needed to identify effective interventions to prevent post-acute diarrhea outcomes.

Keywords: Pediatric diarrhea management, Child growth, Diarrhea interventions, Child mortality, Long-term sequelae of diarrhea

\section{Background}

Close to 600,000 children die each year from diarrheal disease, the majority in low- and middle-income countries (LMICs) [1]. Children with a single episode of moderateto-severe diarrhea (MSD) experience an 8.5-fold higher risk of dying in the 60-days following the episode compared to age-matched healthy children, despite standard

\footnotetext{
* Correspondence: ppav@uw.edu

${ }^{1}$ Department of Global Health, University of Washington, Seattle, WA, USA

Full list of author information is available at the end of the article
}

diarrhea case management including rehydration and zinc [2]. A verbal autopsy study conducted in 7 LMICs found that $55.6 \%$ of pediatric diarrhea deaths occurred in children who had been rehydrated [3]. Although rehydration and zinc have resulted in millions of lives saved from diarrhea, they may be insufficient to prevent all diarrheaassociated mortality.

The consequences of diarrhea extend beyond acute dehydration and electrolyte imbalance. Over two-thirds of deaths associated with diarrhea occur more than 7 days after presentation [2]. An episode of MSD is also 
associated with subsequent loss of length/height-for-age z-score (LAZ/HAZ), a measure of chronic malnutrition $[2,4]$. Undernutrition is linked to half of all diarrheaassociated mortality and is associated with other longterm outcomes including reduced school attendance and future earning potential $[2,5,6]$.

While mortality from diarrheal diseases has declined since the 1990's, incidence rates have remained stable and there is increasing recognition of the morbidity, disability, and long-term consequences associated with diarrhea. We conducted a systematic review to identify and summarize randomized controlled trials (RCTs) of diarrhea management interventions to determine effects on death, anthropometric status, and prevalence and incidence of diarrhea in the post-acute period.

\section{Methods}

The systematic review followed PRISMA guidelines. We searched Medline for English-language RCTs published between January 1, 1980 and October 31, 2016 conducted among children under 15 years of age presenting with diarrhea (all diarrhea definitions accepted) at the time of treatment. Specifically, we searched for trials evaluating 1 of the following interventions: antiemetics, antibiotics, antiprotozoals, antisecretories, dietary supplements, intravenous hydration therapy, oral rehydration therapy, probiotics, prebiotics, lactose replacement, and therapeutic zinc. These interventions were chosen based on consultation with experts in the field. The search terms used were as follows:

)((()(()((()antibiotic OR antiinfective OR anti-infective OR antimicrobial OR antiparasitic OR anti-parasitic OR antiprotozoa* OR anti-protozoa* OR ciprofloxacin OR erythromycin OR metronidazole OR antiemetic* OR anti-emetic OR anti-vomit* OR antidiarrheal OR secretoinhibit* OR antipropulsive OR antisecret* OR antisecret OR breast* OR formula* OR milk OR wean* OR treatment OR management OR "amylose maize starch" OR hams OR lams OR prebiotics OR "resistant starch" OR bifidobacter* OR lactobacill* OR lactococc* OR microbi* OR probiotic* OR fluid OR intravenous OR IV OR ORS OR "oral rehydration salt" OR ORT OR "oral rehydration therapy" OR polymer OR rehydration OR minerals OR zinc)))) AND (“1980/01/01"[Date - Publication]: "2016/10/31"[Date - Publication])) AND (((“bloody stool" OR diarrh" OR dysentery OR gastroenterit*))))) AND ((((clinical trial) OR placebo-controlled trial) OR randomized controlled trial))))) NOT cancer) NOT antibiotic associated diarrhea)

Filters: Clinical Trial; Humans; English; Child: birth18 years

We excluded studies in 2 steps. The first step aimed to exclude trials that did not address the populations or interventions of interest. Specifically, studies conducted in high-income countries (as defined by the World Bank as of June 2015) [7], those that did not include children with diarrhea at enrollment, utilized a design other than an RCT, or did not present individual-level outcome data were excluded in the first round. The second round excluded trials with insufficient follow up (less than 7 days) and those that lacked outcome data on mortality, length/height, LAZ/HAZ, weight, weight-for-age z-score (WAZ), weight-for-height z-score (WHZ), mid upper arm circumference (MUAC), or diarrhea presence at a pre-specified follow-up point $\geq 7$ days after enrollment. Although weight may be misclassified during diarrhea illness due to fluid loss, in the context of an RCT, groups were assumed to be balanced with regard to hydration status. Therefore, weight, WAZ, and WHZ were considered valid outcomes. Diarrhea duration (other than presence of diarrhea at a pre-specified time point beyond 7 -days) and stool output were not included as outcomes because they were considered intermediate to the outcomes of interest in this review.

All titles and abstracts were screened by 2 reviewers (PBP and HEA) and abstracts of agreed-upon titles were examined for inclusion. Full texts of agreedupon abstracts were reviewed for inclusion by RLB and HEA with final input from PBP. The following study-specific information was abstracted from included trials: intervention, control group, population, dates of enrollment, sample size, duration of follow up, reported outcomes, and data on effect sizes of relevant outcomes, and associated confidence intervals (CIs). Details on data abstraction and calculations are provided in the supplementary material for this manuscript (Additional file 1).

A modified Grading of Recommendations Assessment Development and Evaluation (GRADE) approach was developed to assess study design elements including sample size, number of participants lost to follow up or withdrawn from the study, and blinding and allocation concealment methods to evaluate the quality of studies. We did not assess the GRADE elements of directness or consistency, as these elements are specific to results reported within a given intervention and outcome category and this review assessed multiple interventions and outcomes. All trials started with 4 points because all were randomized controlled trials and 1 point was deducted for each of the following elements: sparse data $(<200$ trial participants), $>5 \%$ loss-to-follow-up or withdraws, or lack of double-blinding. Reviewers (HA and RB) applied the modified GRADE system included in this review and categorized each study as high quality (4 points), moderate (3 points), low ( 2 points), or very low (1 point) based on their final score. In addition to the elements required for GRADE, from included trials we abstracted whether or not a primary endpoint was declared (and whether the primary endpoint was 1 of the endpoints included in this 
review) and any mention of power calculations for included outcomes.

\section{Results}

The Medline search returned 2815 titles, of which 693 abstracts and 432 full texts were reviewed, and 385 excluded based on full-text review (Fig. 1). Among the 314 studies that were eligible based on study location, design, and population (included based on first exclusion step), most (205 [65.2\%]) were excluded for failure to meet our criteria for length of follow up (7 days or more) and 51 (16.2\%) were excluded because no outcomes of interest were reported in the second exclusion phase.

Forty-six trials were included in this review, the majority (27 studies [58.7\%]) of which were conducted in the WHO-classified Southeast Asia region [8-34], with 19 (70.4\%) conducted in Bangladesh alone (Table 1). Seven studies (15.2\%) were conducted in the Americas [35-41], 7 studies (15.2\%) reported data from Africa [42-48], 2 from the Eastern Mediterranean (Pakistan) $[49,50]$ and 2 from Europe (Turkey) [51, 52]. One study was conducted in 3 countries (Ethiopia, Pakistan, and India) [53]. The majority of the trials were conducted in inpatient settings (35 studies, $76.1 \%)$. Five $(10.9 \%)$ trials were communitybased, and the remaining 6 (13.0\%) were conducted in outpatient settings. The most common interventions included therapeutic zinc (15 studies [32.6\%], 2 of which was assessed in the same trial as vitamin A), and high protein diets (9 studies [19.6\%]). Probiotics were assessed in 5 studies (10.9\%), and 5 trials evaluated lactose-free diets $(10.9 \%)$. Four were trials of ORS formulations (8.7\%), and $3(6.5 \%)$ trials evaluated dietary supplements, including dietary fiber (2 studies), and glutamine (1 study). Three (6.5\%) trials were of other dietary interventions, a semi-elemental diet and 2, 3-armed trials evaluated readyto-use therapeutic food (RUTF) or micronutrient powder. Only $2(4.3 \%)$ of the trials that fit our inclusion criteria evaluated antimicrobial treatments (1 antibiotic and 1 antiprotozoal). We did not find any trials of intravenous (IV) rehydration, antisecretory agents, or antiemetic agents that met our inclusion criteria. The sample size of included studies ranged from 18 to 8070 and only 11 (23.9\%) of the 46 trials included more than 200 participants (1 ORS, 2 probiotic, 2 RUTF/micronutrient, 1 vitamin A + zinc, and 5 zinc trials). Just over half of included trials (52.2\%) reported power/sample size calculations, the majority of which (11 [48\%] of the 23) were powered for the outcome of diarrhea duration/stool output, outcomes not included in this systematic review.

Of the 46 clinical trials evaluated using the modified GRADE system, 6 (13.0\%) scored high, 8 (17.4\%) scored moderate, 11 (23.9\%) scored low, and 21 (45.7\%) scored very low (Table 1 ). The most common deduction was for sparse data (35 [76.1\%]), followed by deductions related to follow-up and withdrawals (24 [52.2\%]), or blinding/allocation process (21 [45.7\%]).

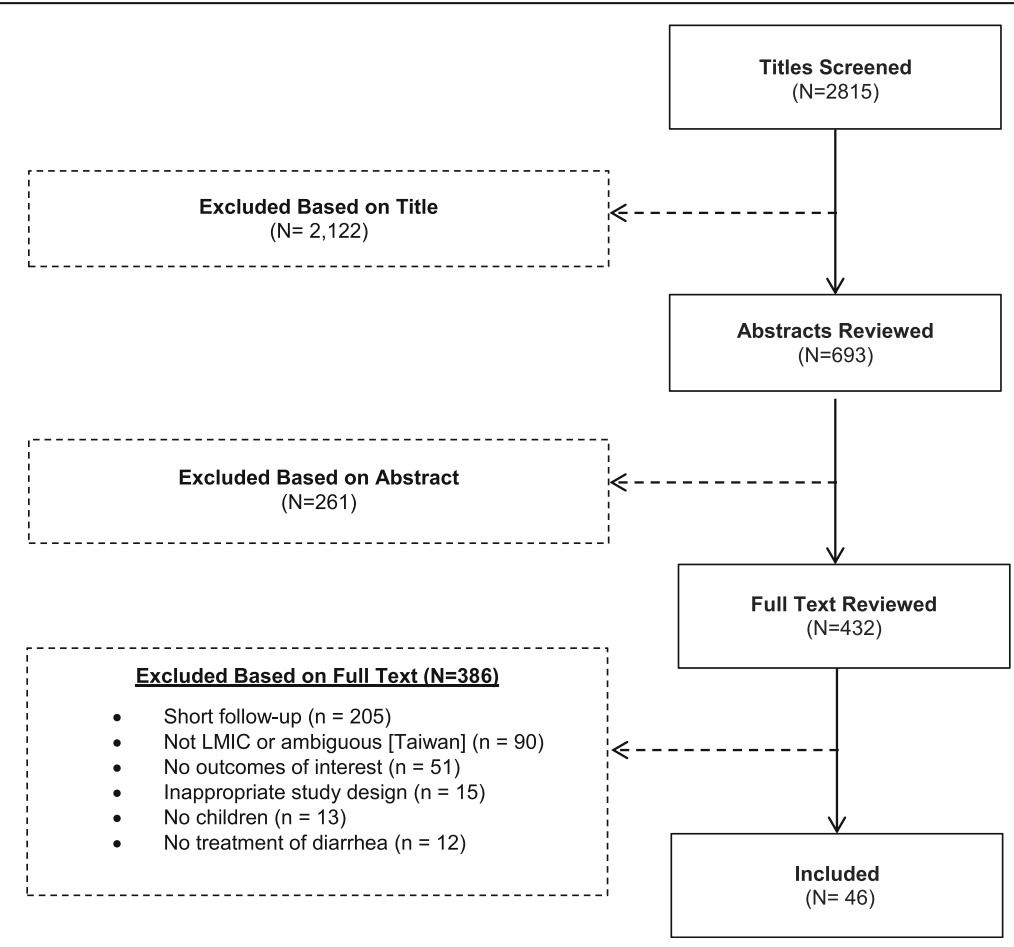

Fig. 1 Flow chart of included trials of diarrhea management interventions 


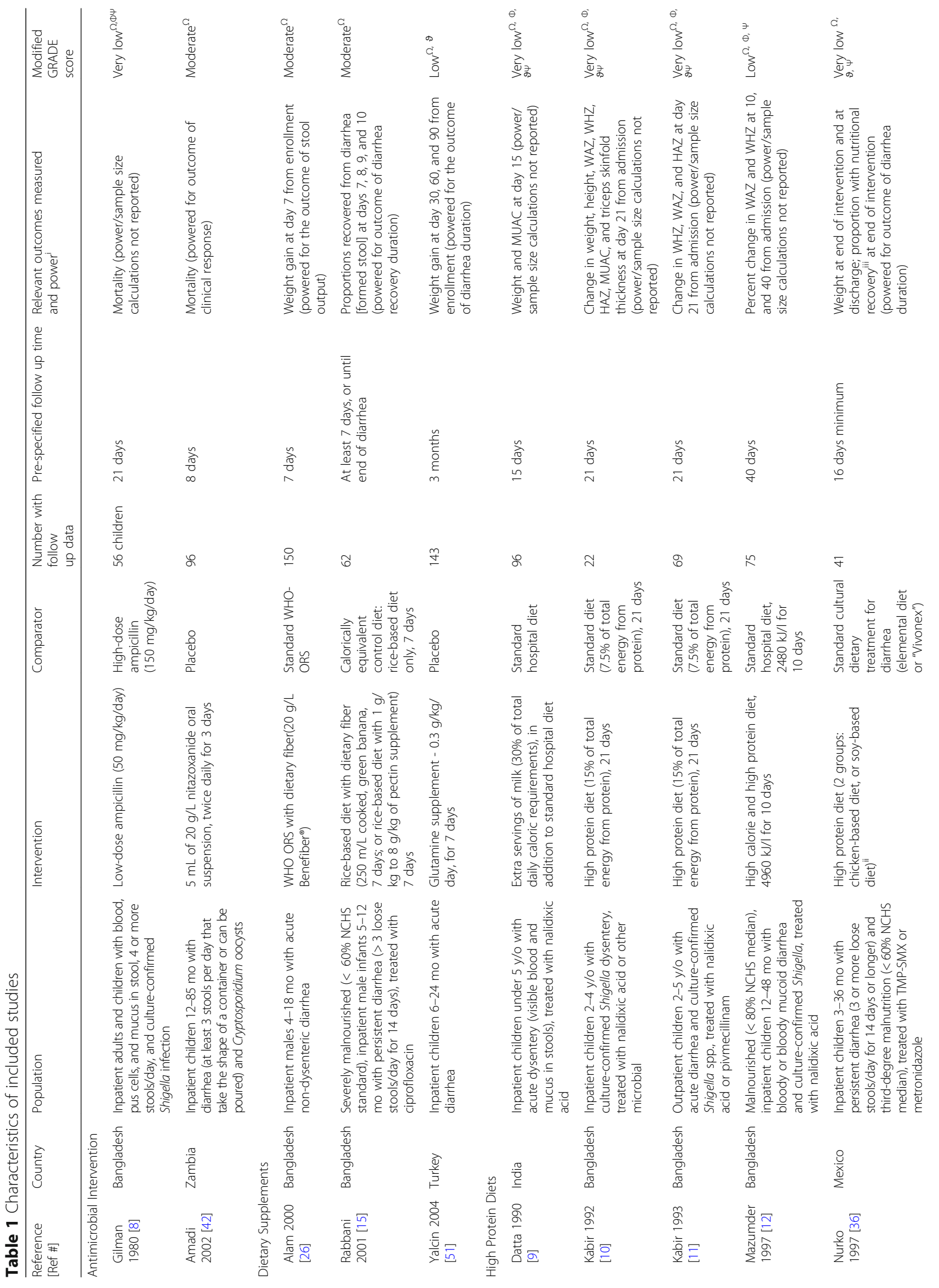




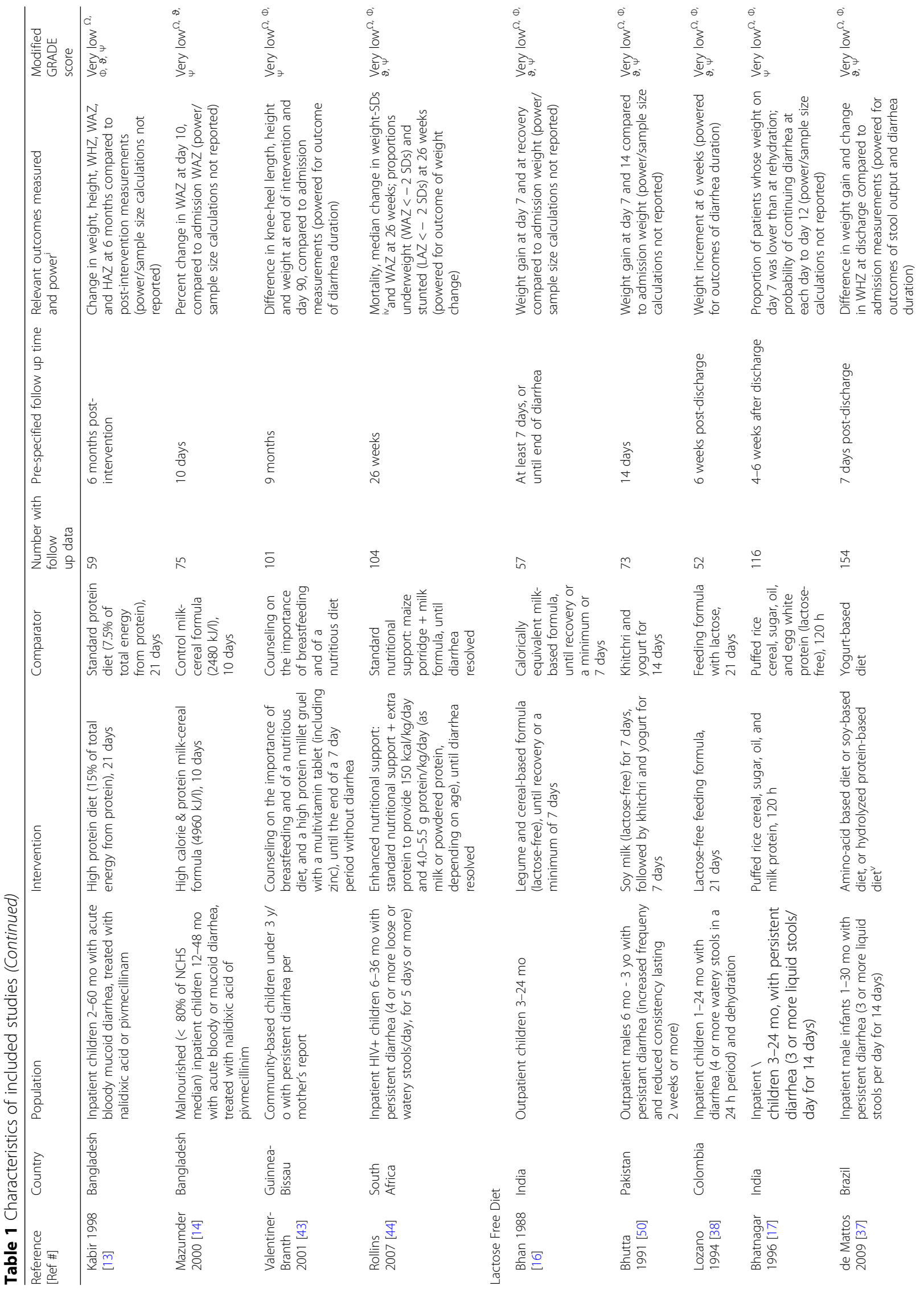




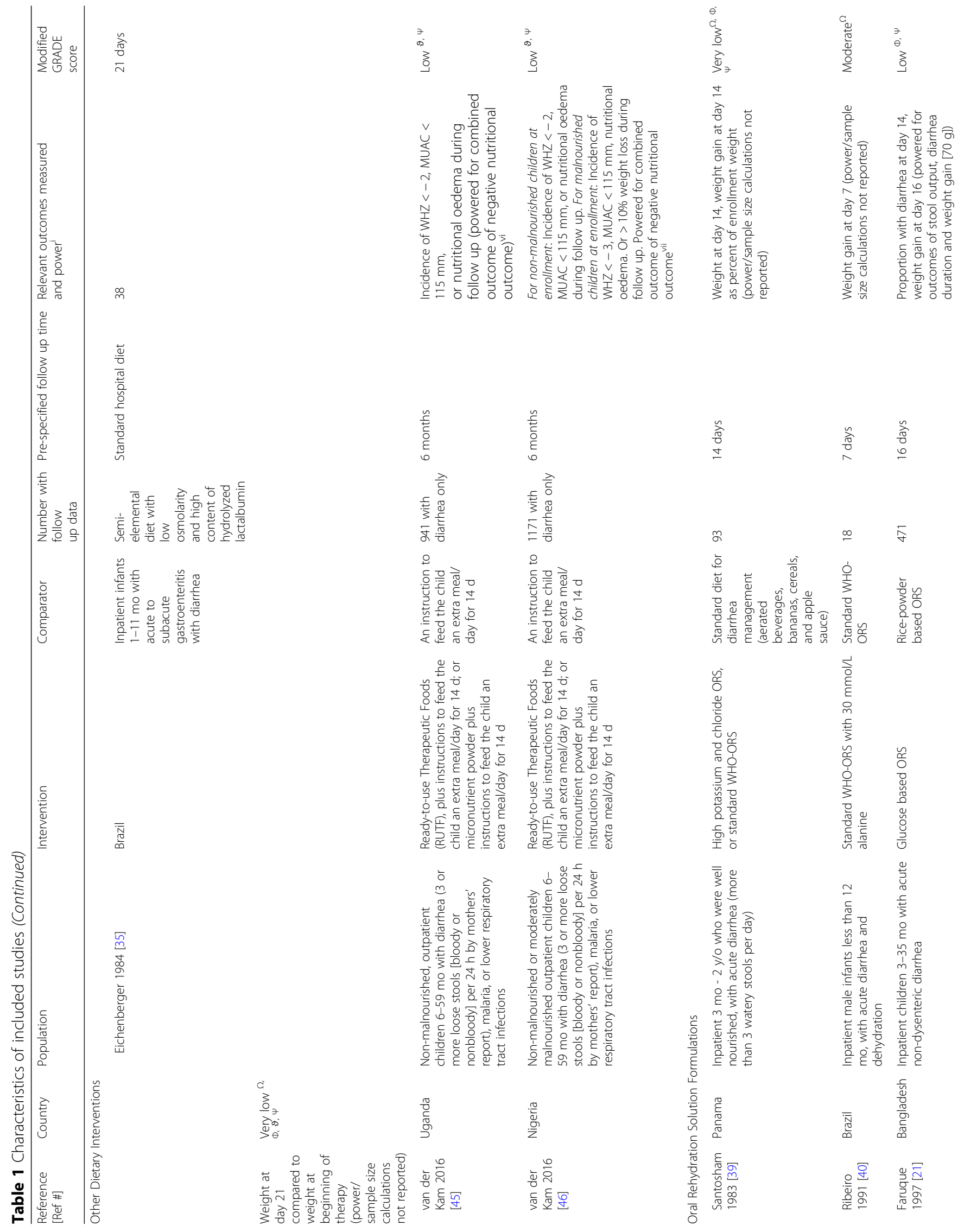




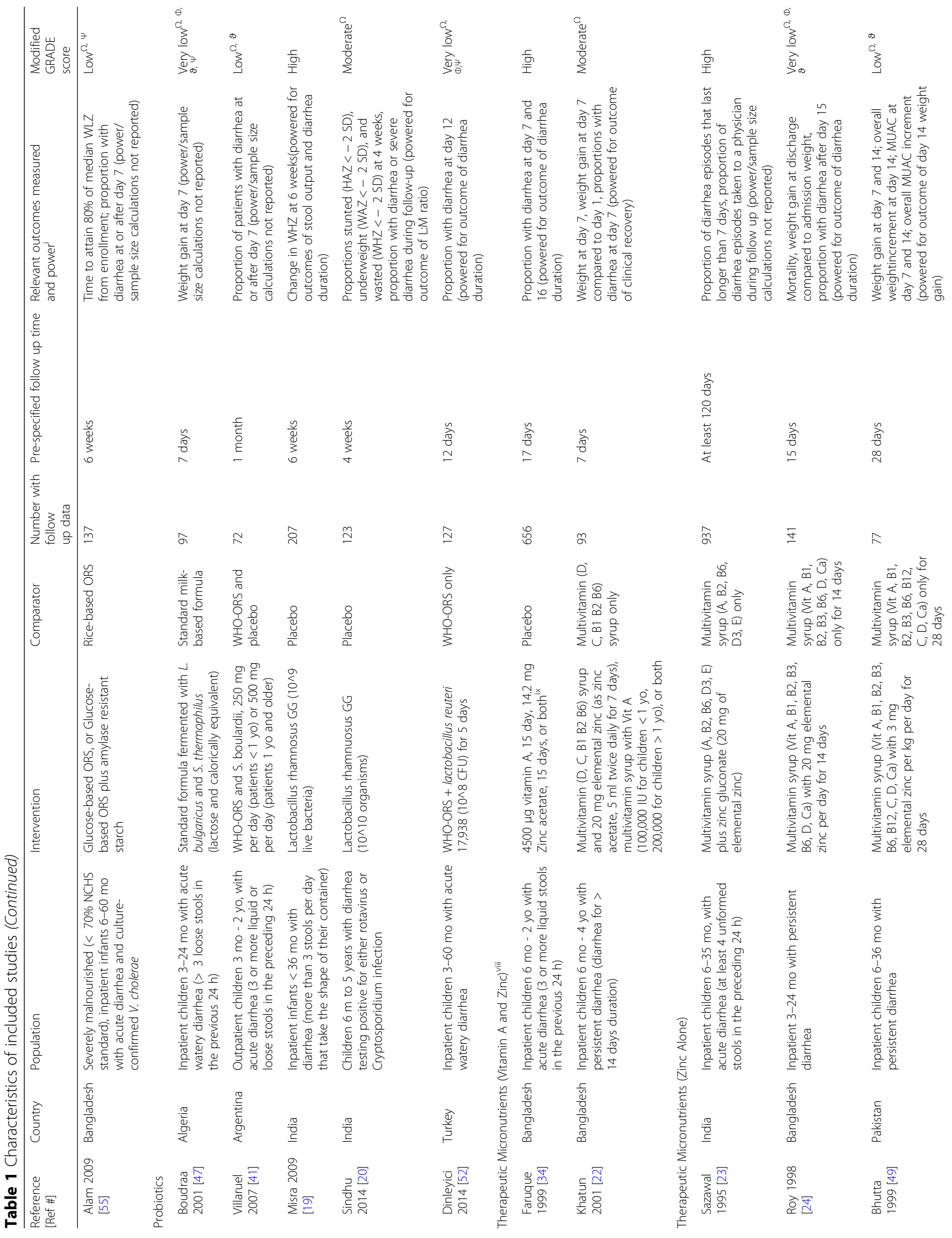




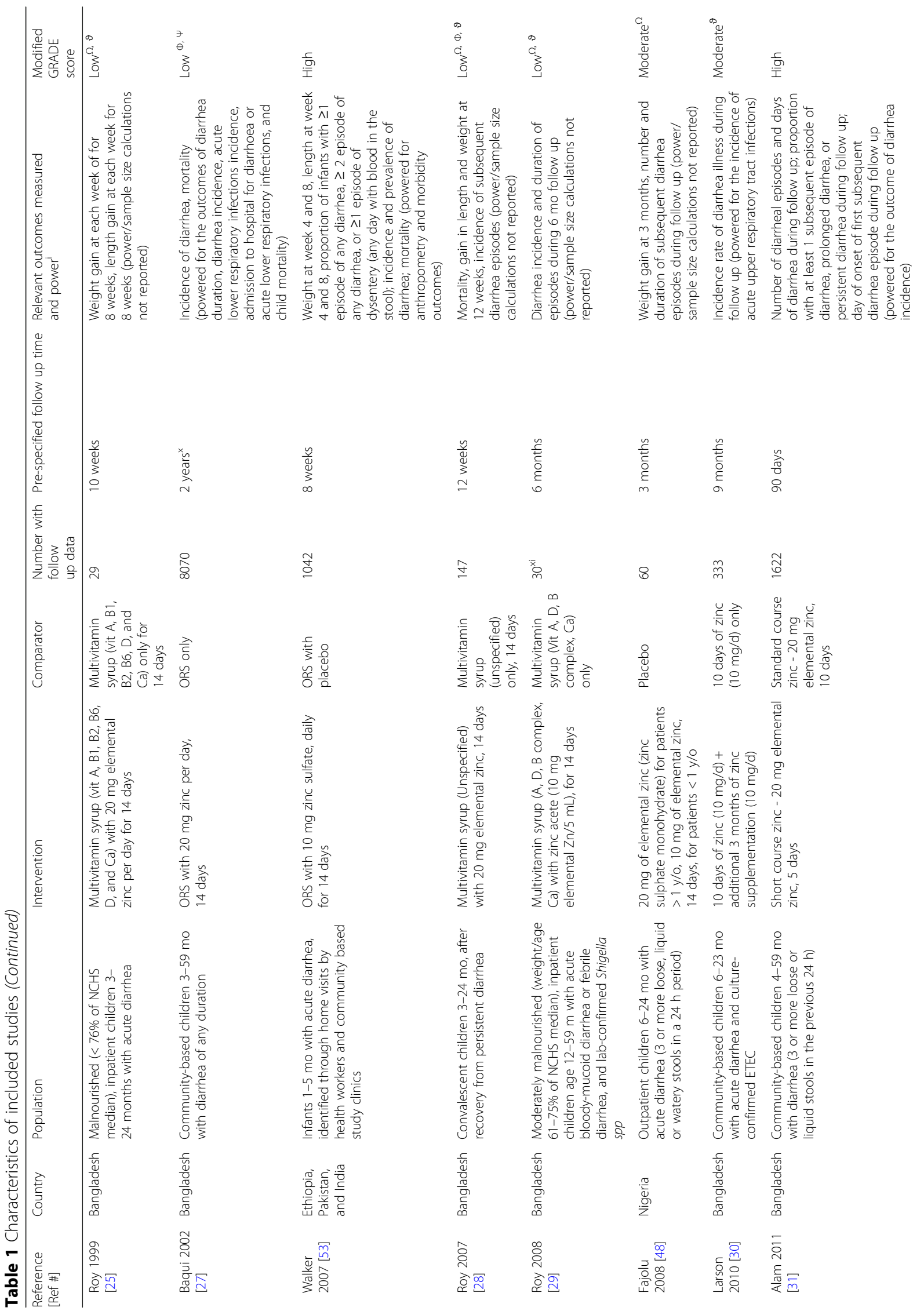




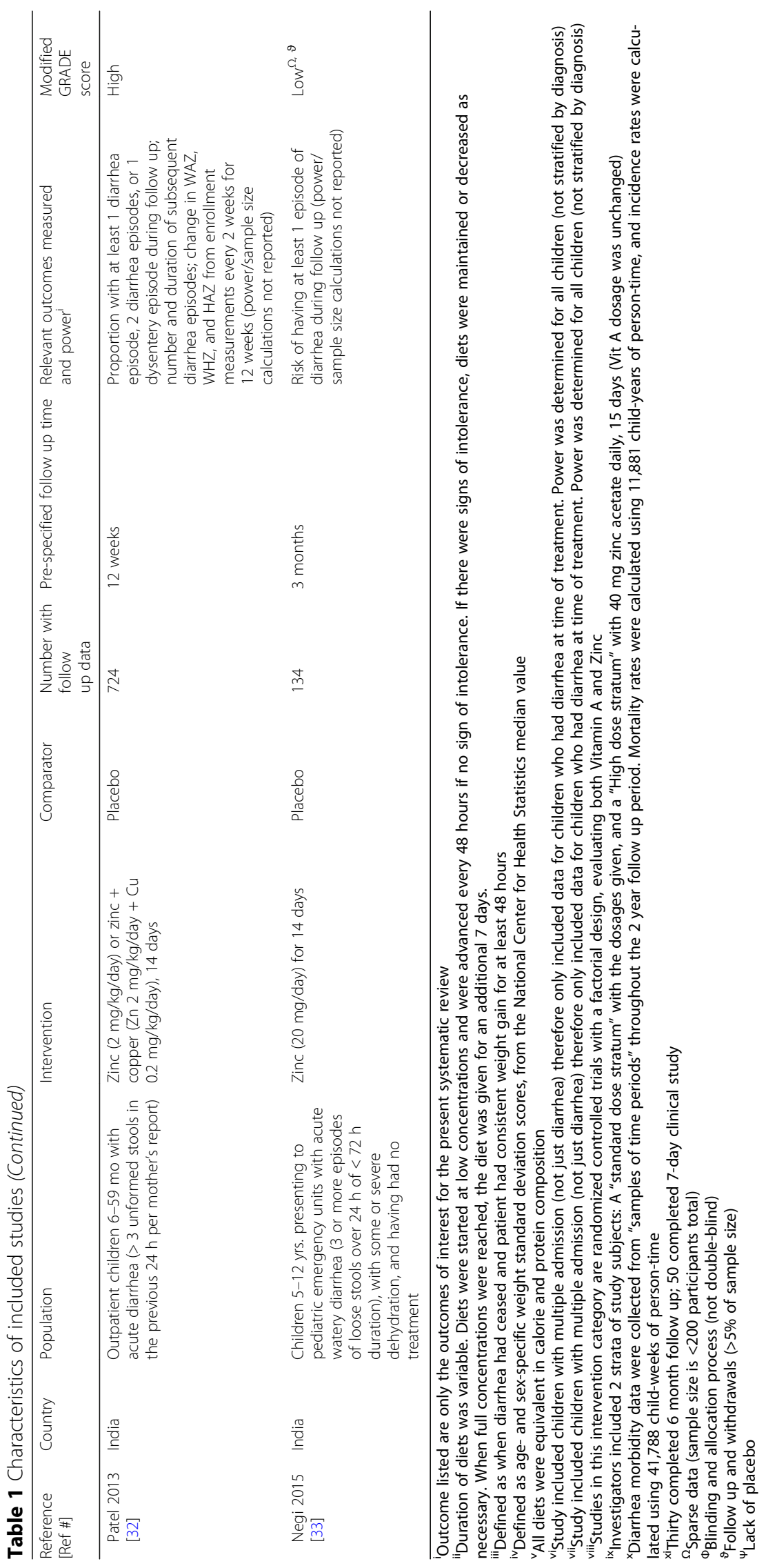




\section{Mortality}

Seven studies (15.2\%) presented data on post-acute mortality, with follow-up ranging from 8-days to 2 years. Four were trials of therapeutic zinc interventions, [24, 27, 28, 53], 2 antimicrobial treatments [8, 42], and 1 of a high protein diet [44]. Two of the zinc trials were large studies (8070 and 1042 subjects, respectively) [27, 53] but the remaining 5 included less than 150 participants (Fig. 2, Table 2). None of the 7 trials were adequately powered for a mortality endpoint. Only 1 trial, a cluster randomized trial of zinc, found a lower non-injury mortality rate in children living in communities randomized to ORS and zinc compared to those using ORS alone (relative risk $[R R]=0.49$ [95\% confidence interval $\{95 \% \mathrm{CI}\}: 0.25,0.94]$ ] [27]. The remaining 6 studies reported non-significant risk differences ranging in magnitude from 70 more to 105 less deaths per 1000 children $[8,44]$ and relative risks ranging from 0.18 to 1.34 [24, 44].

\section{Growth}

Studies reported impact on growth in several different ways:

\section{Height/Length, HAZ//LAZ}

Ten studies presented data related to length or height, with follow-up time ranging from 21 days to 9 months and none reported sample size calculations/being powered for these outcomes (Table 1). Five trials evaluated a high protein diet, 4 therapeutic zinc and 1 probiotic. Of 4 studies that reported difference in change in $(\Delta)$ HAZ/LAZ between intervention groups, 1 high protein diet trial reported a $0.9 \mathrm{z}$-score greater gain in HAZ/LAZ in the intervention group after 3 weeks of follow-up (95\% CI: 0.05, 0.13), [11] but 2 high protein diet trials (with 3 and 29 weeks of follow-up) and a large zinc with 12 weeks of follow-up trial found no significant benefit (Fig. 3a) [10, 13, 32]. Four studies presented data on $\Delta$ absolute height at follow-up, 2 of which were trials of high protein diets with follow-up times of 3 and 29 weeks. Of the 2 high protein diet trials, the trial with 29 weeks of follow-up found a benefit in height change (Fig. 3b) - a $1.10 \mathrm{~cm}$ greater change in height compared to the control groups (95\% CI: $0.56,1.64)[10,13]$. Of the other 2 studies evaluating height attainment, a trial of a high protein diet with micronutrients with 36 weeks of follow-up, and another of therapeutic zinc with 8 weeks of follow-up, only the former showed benefit (a greater gain in height of $0.65 \mathrm{~cm}$ in the intervention group [95\% CI: 0.11, 1.19]) [43, 53]. Percent $\Delta$ length was evaluated in 2 therapeutic zinc studies, both of which found a significantly greater length gain among children treated with zinc, but this result was only among underweight children in 1 of the trials [25, 28]. Among 2 studies evaluating prevalence of stunting during follow-up, 1 found that the group treated with probiotics (L. rhamnosus GG) had higher stunting prevalence at 4 weeks of follow-up [54] and a high protein diet trial reported no significant difference at 26 weeks [44].

\section{MUAC}

Four studies reported MUAC data during follow-up periods ranging from 15 to 28 days, 2 were high protein studies, 1 was a trial of therapeutic zinc, and 2 trials of RUTF/micronutrient (which assessed MUAC as 1 of the indicators of acute malnutrition). One of the high protein diet studies reported that children in the intervention group gained $0.44 \mathrm{~cm}$ more in MUAC on average compared to children given a standard protein diet $(95 \%$ CI: 0.08, 0.80) [10]. However, neither the remaining high protein diet study nor the zinc trial reported a significant difference in MUAC during follow-up $[9,50]$. None of the studies provided sample size estimates making it

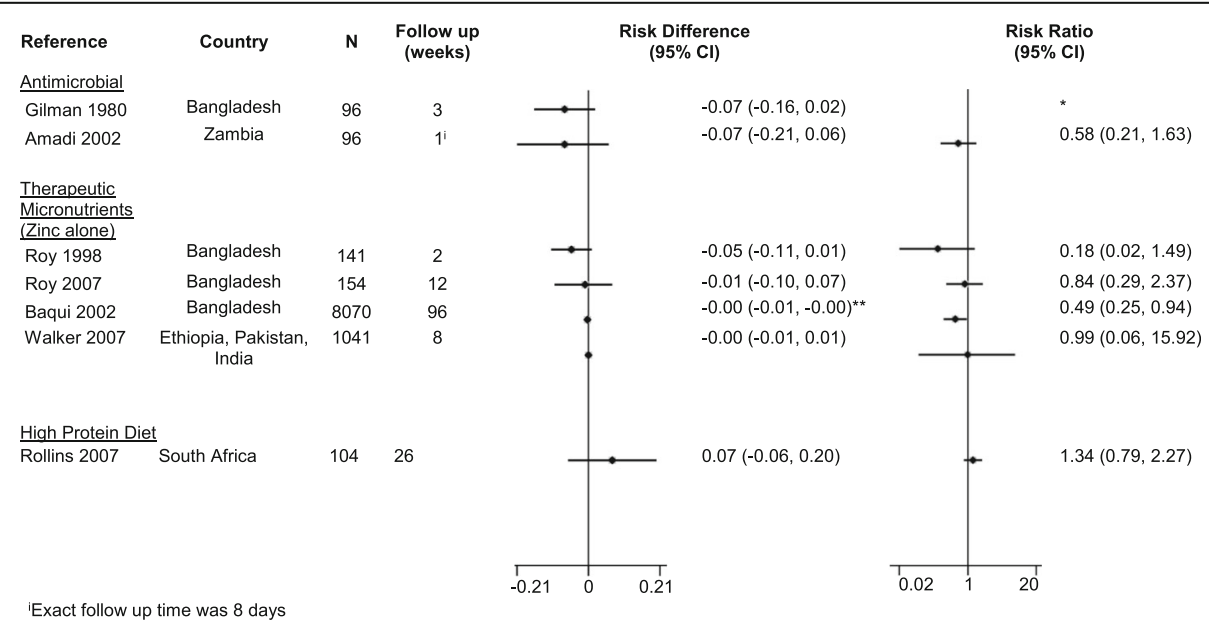

Fig. 2 Effect of diarrhea management interventions on mortality (relative risk, risk difference, and associated 95\% confidence interval) 


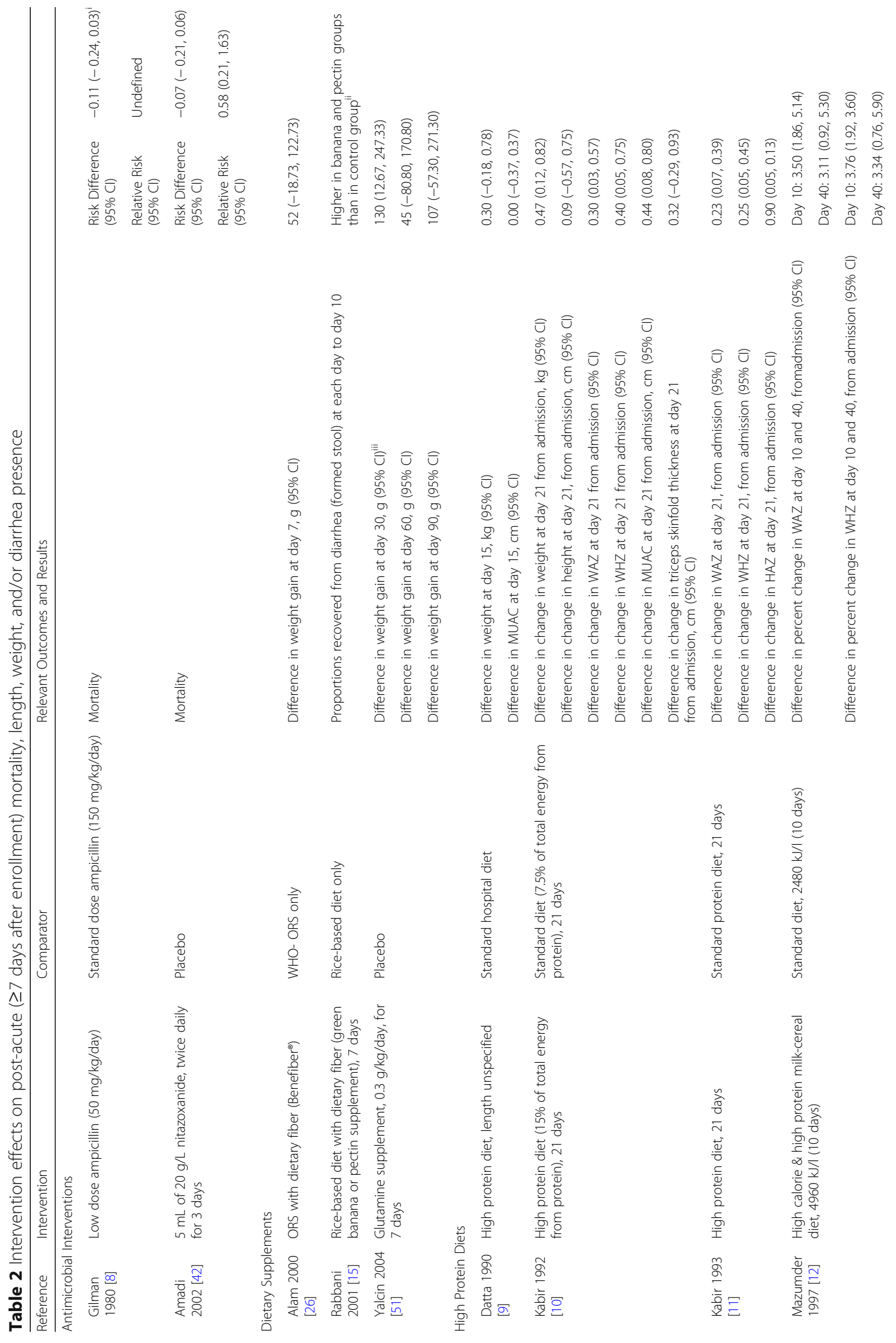




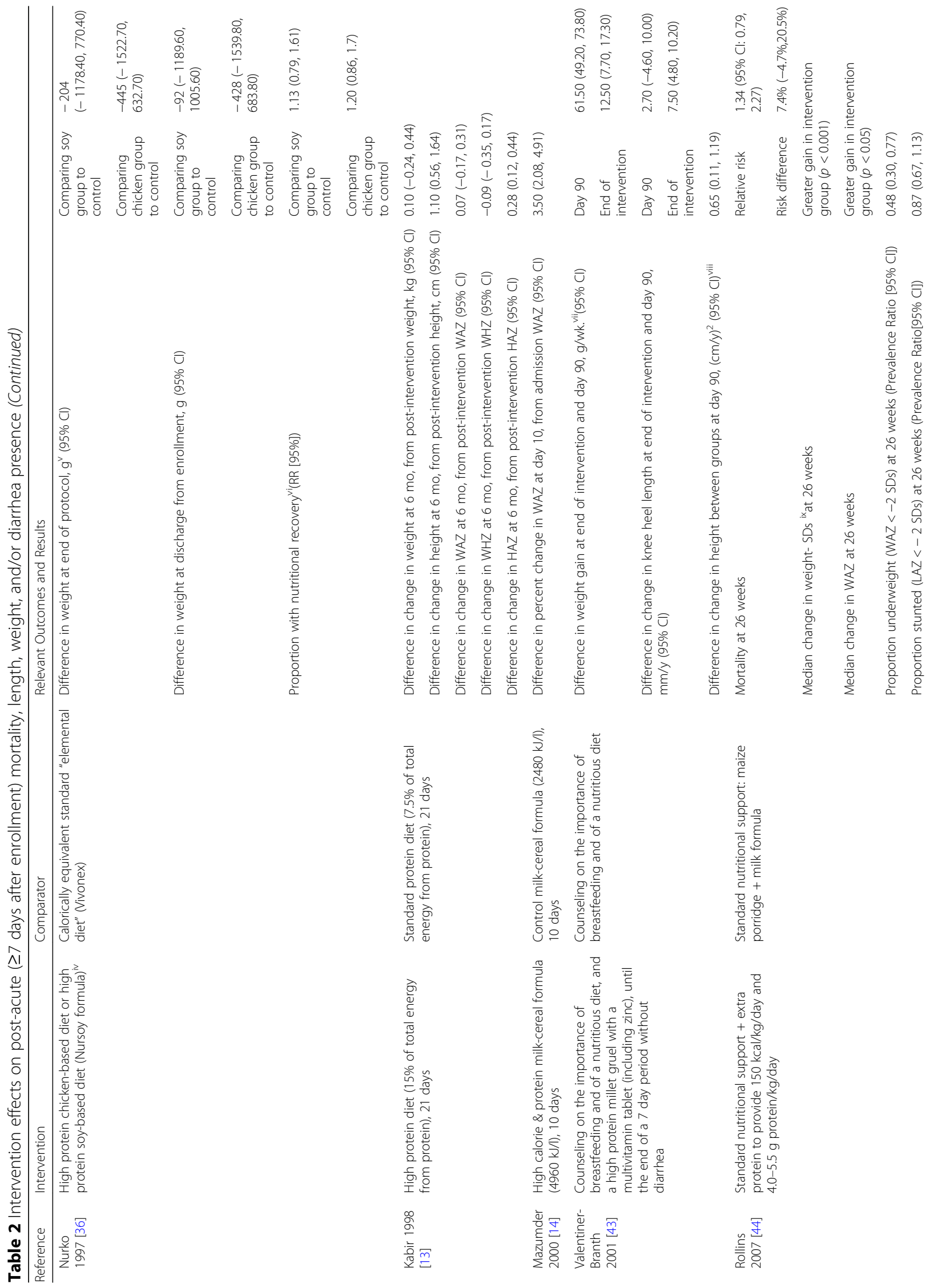




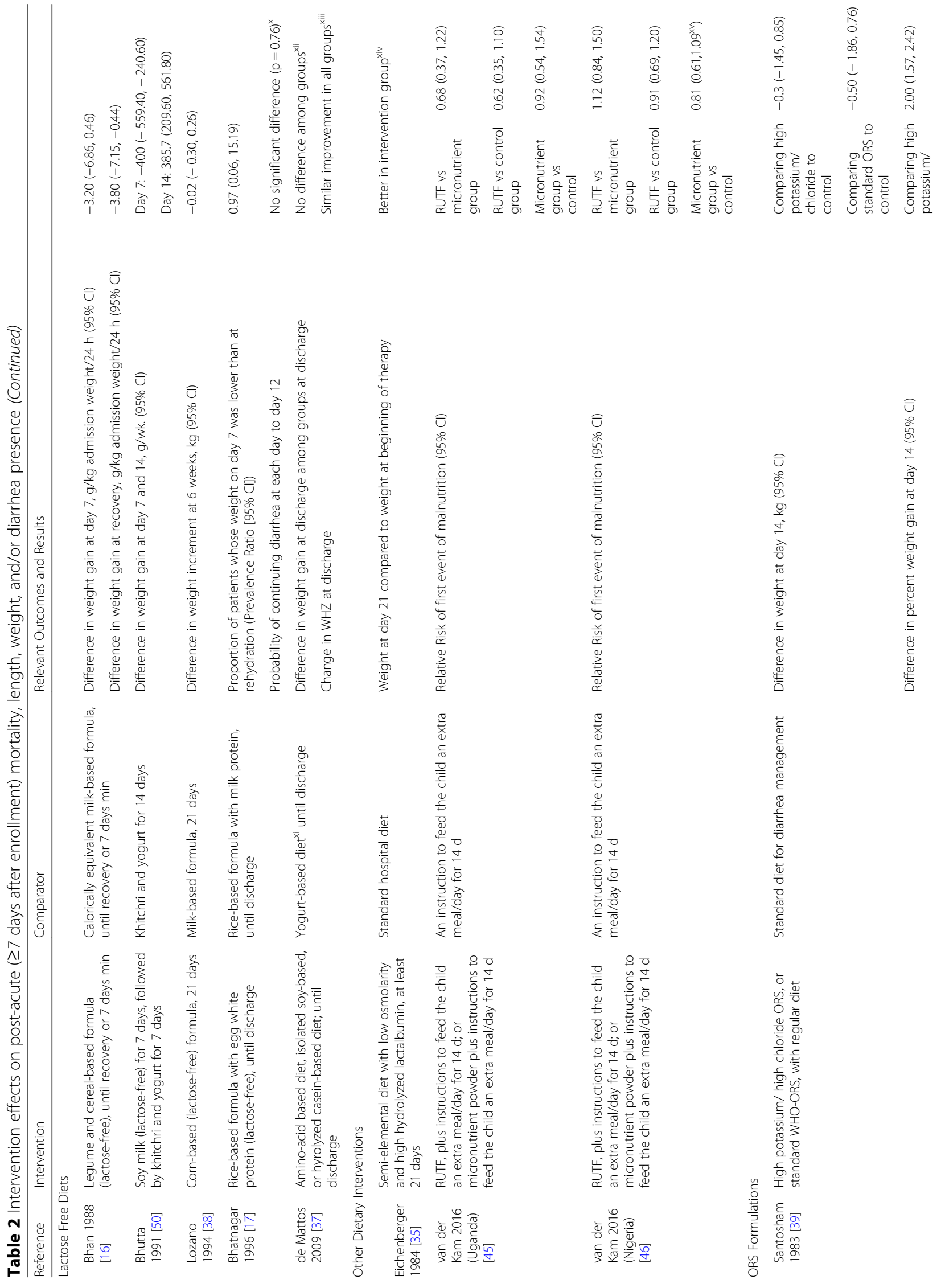




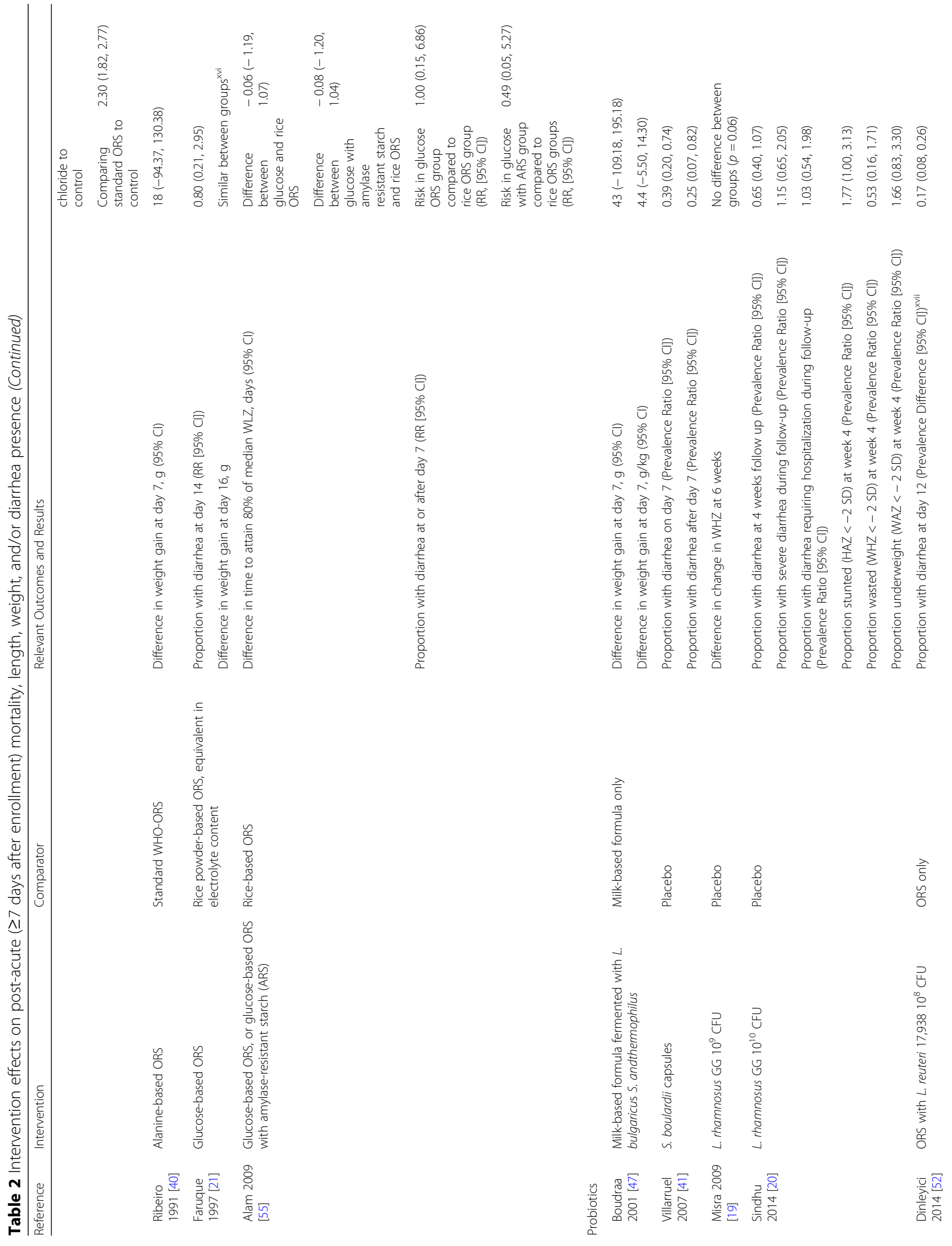




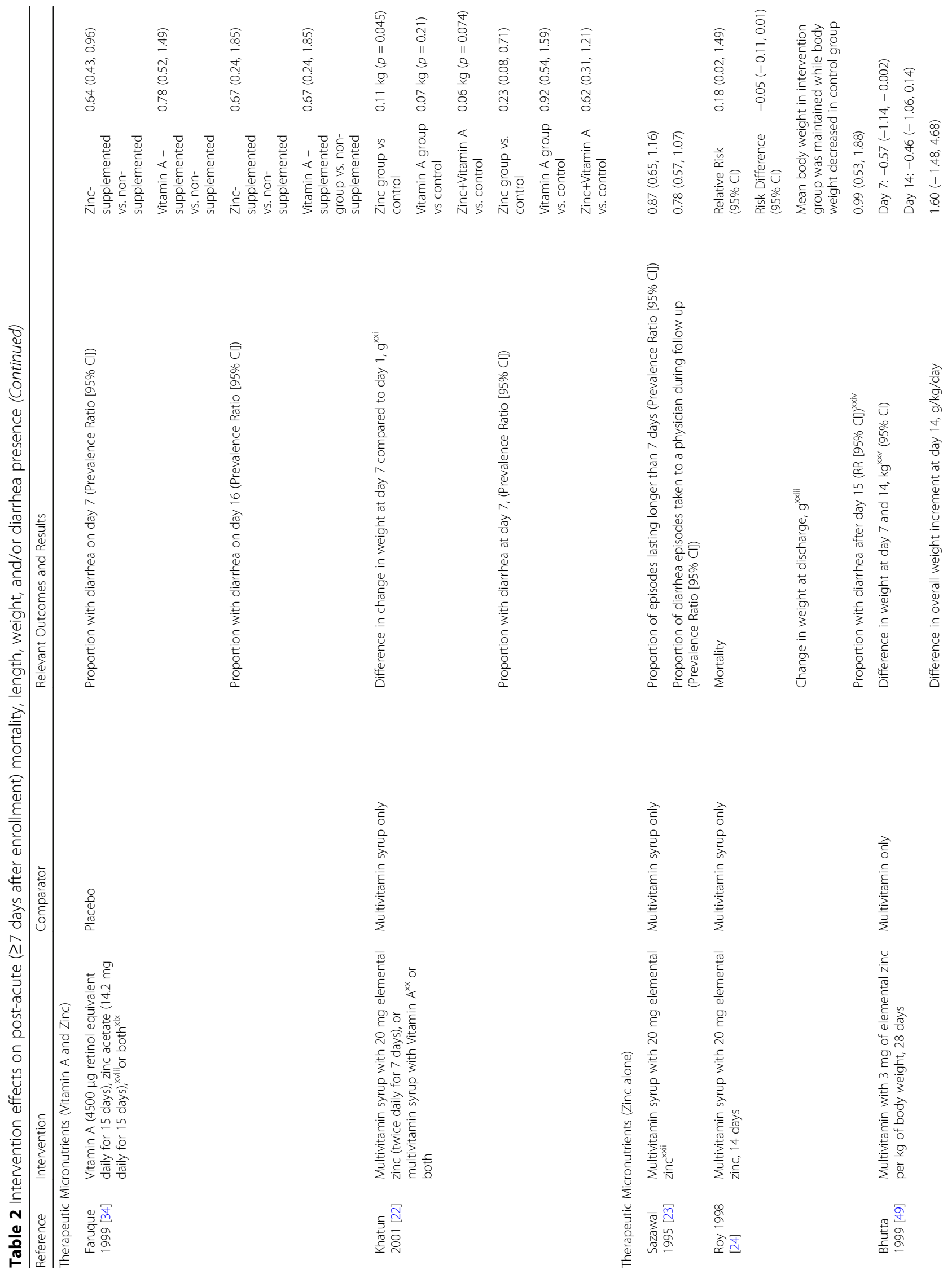




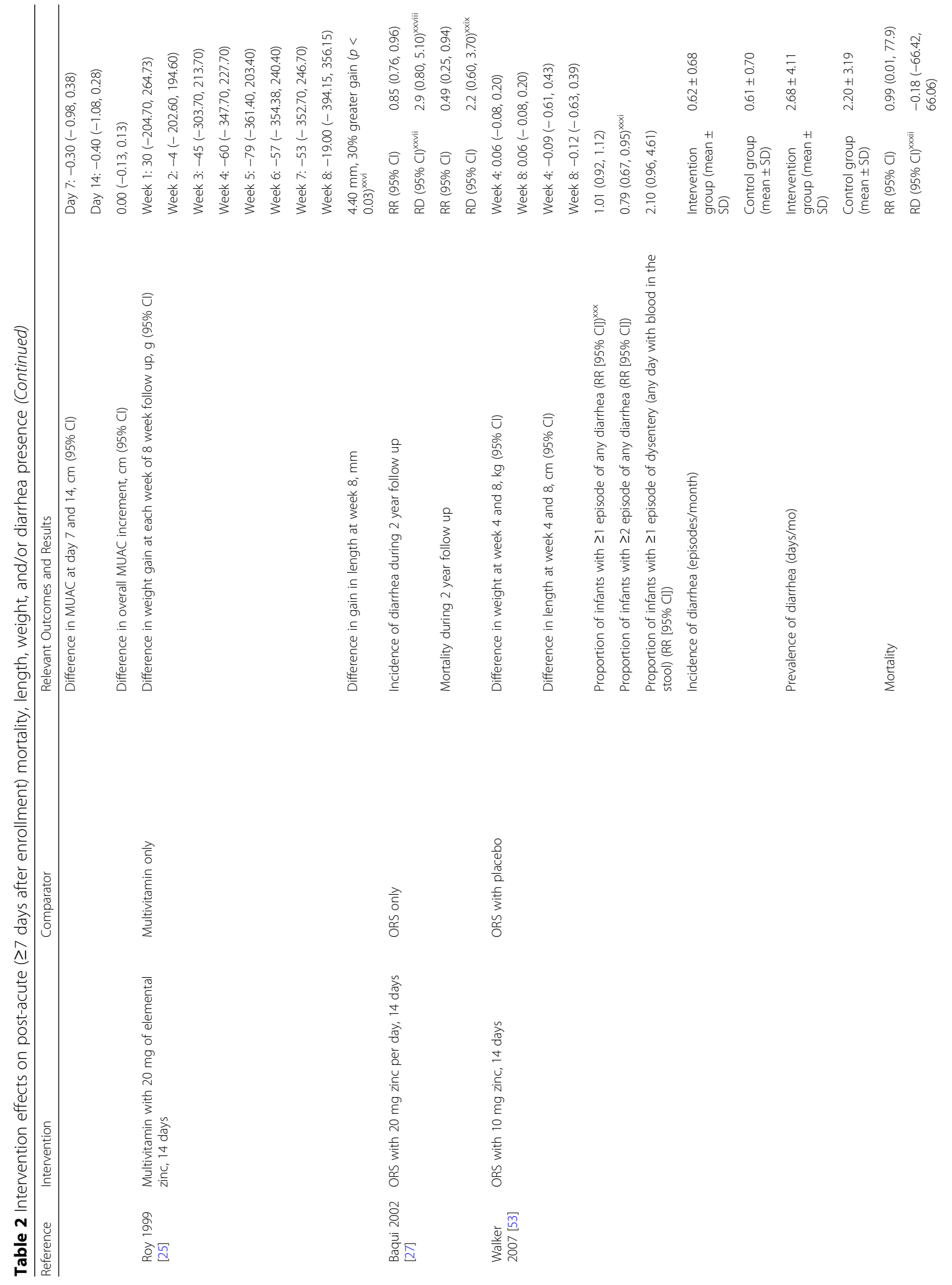




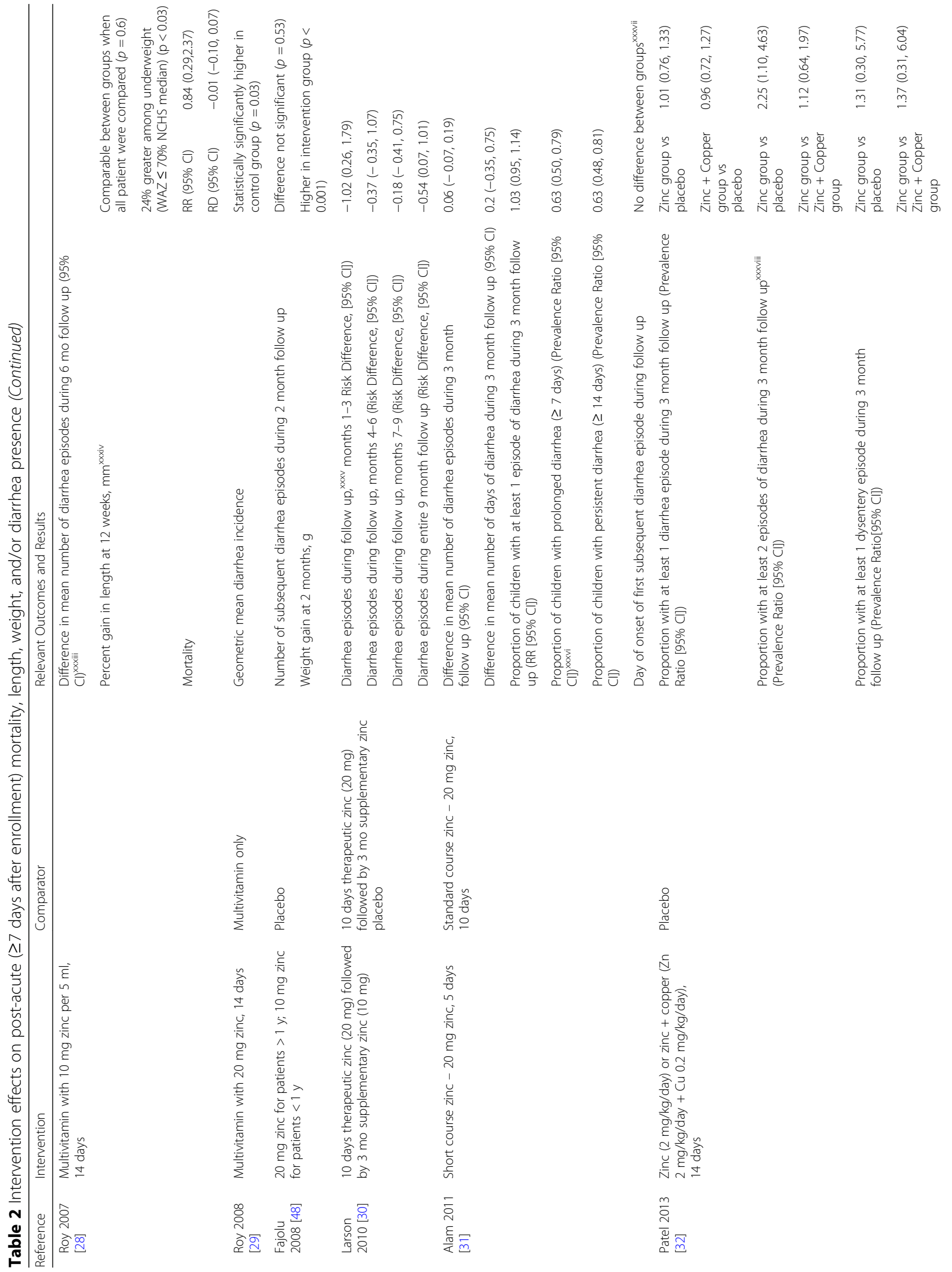




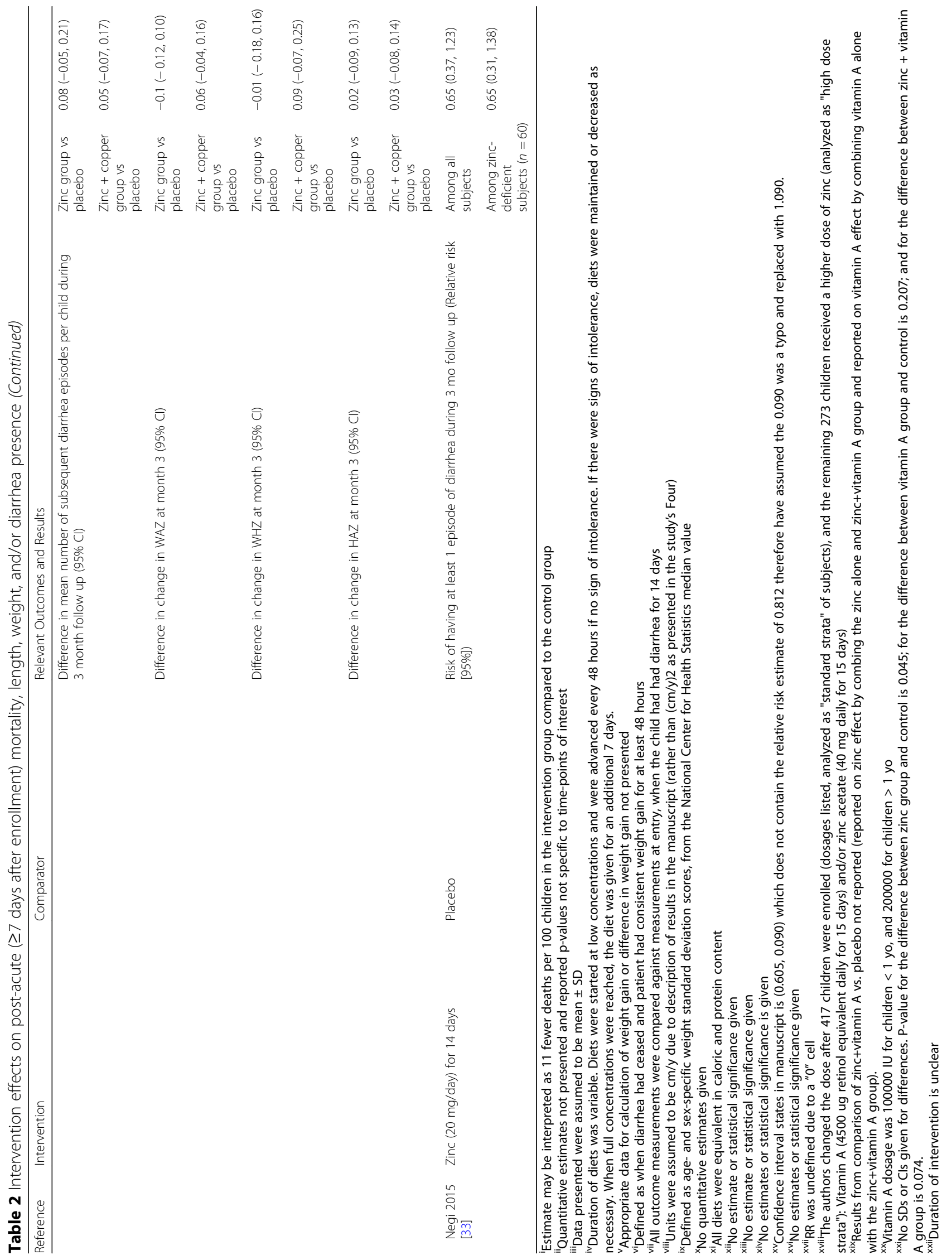




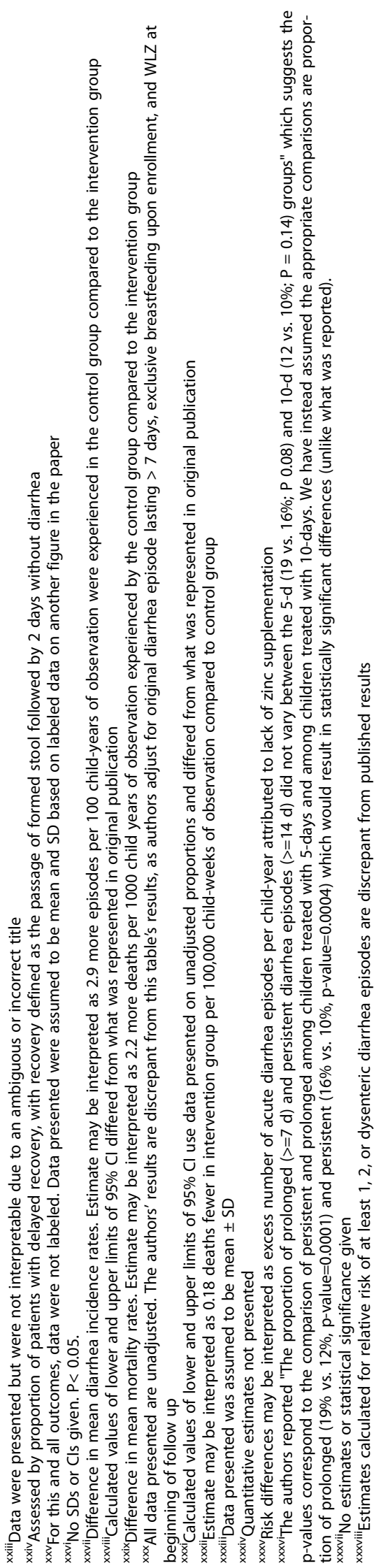




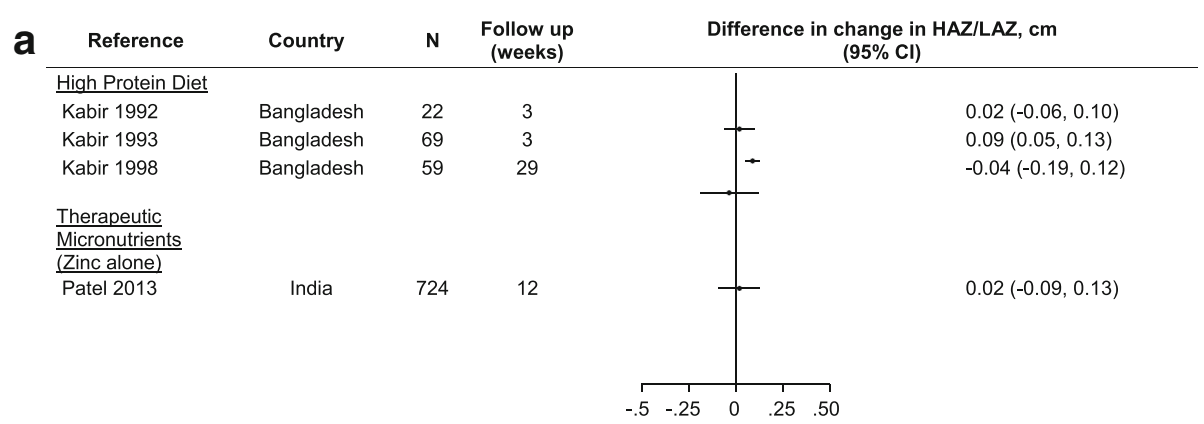

\begin{tabular}{|c|c|c|c|c|c|}
\hline Reference & Country & $\mathbf{N}$ & $\begin{array}{l}\text { Follow up } \\
\text { (weeks) }\end{array}$ & \multicolumn{2}{|c|}{ Difference in change in height, $\mathrm{cm}(95 \% \mathrm{Cl})$} \\
\hline \multicolumn{6}{|l|}{ High Protein Diet } \\
\hline Kabir 1992 & Bangladesh & 22 & 3 & 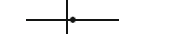 & $0.09(-0.57,0.75)$ \\
\hline Kabir 1998 & Bangladesh & 59 & 29 & $\longrightarrow$ & $1.10(0.56,1.64)$ \\
\hline $\begin{array}{l}\text { Valentiner- } \\
\text { Branth } 2001\end{array}$ & Guinea-Bissau & 101 & 36 &. & $0.65(0.11,1.19)$ \\
\hline \multicolumn{6}{|l|}{$\begin{array}{l}\text { Therapeutic } \\
\text { Micronutrients } \\
\text { (Zinc alone) }\end{array}$} \\
\hline Walker 2007 & $\begin{array}{l}\text { Ethiopia, } \\
\text { Pakistan, India }\end{array}$ & 1035 & 8 & & $0.01(-0.73,0.75)$ \\
\hline
\end{tabular}

Fig. 3 a Effect of diarrhea management interventions on change in HAZ/LAZ (difference in change in HAZ/LAZ and 95\% confidence interval). b Effect of diarrhea management interventions on change in height (difference in change in height $(\mathrm{cm})$ and $95 \%$ confidence interval)

unclear whether they were adequately powered to detect differences in MUAC. Both trials of RUTF and micronutrient powder reported the incidence of acute malnutrition (WHZ $<2$, MUAC $<115 \mathrm{~mm}$, or oedema) to be similar across all combinations of groups (RUTF vs controls; micronutrients vs. controls, and RUTF vs. micronutrients) in the subgroup of children from both trials who had diarrhea at enrollment $[45,46]$.

\section{WHZ, WAZ, or absolute weight}

Thirty-two trials $(74.4 \%)$ with follow-up periods ranging from 7 days to 29 weeks, reported data on weight, WAZ, or WHZ. Of these, 9 assessed a high protein diet, 7 assessed therapeutic zinc (including 1 which also assessed vitamin A), and 5 tested lactose-free diets. Four were trials of ORS formulations, 3 of probiotics, and 1 each of semi-elemental diet, glutamine, and dietary fiber. Of the 4 trials evaluating differences in $\triangle \mathrm{WAZ}$ between study groups, 3 high protein and 1 therapeutic zinc trials, 2 (both high protein) reported a statistically significant improvement (ranging from 0.23 [11] to 0.3 z-scores [10]) compared to a standard diet (Fig. 4a) although none were explicitly powered for this outcome. The same 2 diet trials also reported a significant benefit in WHZ, with high protein groups gaining 0.25 [31] to 0.4 units [11] more in WHZ than the standard diet group (Fig. 4b) whereas the 2 zinc trials assessing $\triangle W H Z, 1$ of which was explicitly powered to address WHZ, found no difference $[32,53]$. Two additional trials assessed WHZ although did not present quantitative results for calculation of effect size and 95\% confidence intervals; A probiotics trial concluded there was no difference in $\triangle \mathrm{WHZ}$ at 6 weeks between the treated and untreated groups, [19] while a high protein diet trial reported a greater median $\triangle W A Z$ in children given high protein diets at 26 weeks of follow-up [44].

Twenty-two studies presented data on absolute weight gain (Fig. 4c) or weight at follow-up: 6 high protein diet trials, 6 zinc (1 of which also assessed vitamin A), 4 lactose free diets, 2 ORS, and 1 each of a probiotic, semielemental diet, dietary fiber, and glutamine. Three of the 6 high protein trials found a statistically significant improvement in weight associated with the intervention group, $[10,43,44]$ as did 3 of the 6 zinc trials, $[22,25,48] 1$ of which also assessed vitamin A which did not appear to have a weight benefit [22]. Two of the 4 lactose-free diets $[16,50]$ and 1 of 2 ORS trials demonstrated a significant benefit in weight [39]. This trial found a greater percent improvement in weight 14 days after presentation in the groups of children treated with ORS $(90 \mathrm{mmol} / \mathrm{l}$ or $50 \mathrm{mmol} / \mathrm{l}$ of sodium) vs. no ORS but did not find a statistically significant difference when measured as absolute difference in weight. Weight gain was significantly improved in the trial of a semi-elemental diet [35] and the single trial of glutamine found intervention children to have $130 \mathrm{~g}$ more weight gain than the placebo group at follow-up day 30, but not at days 60 or 90 of follow-up 


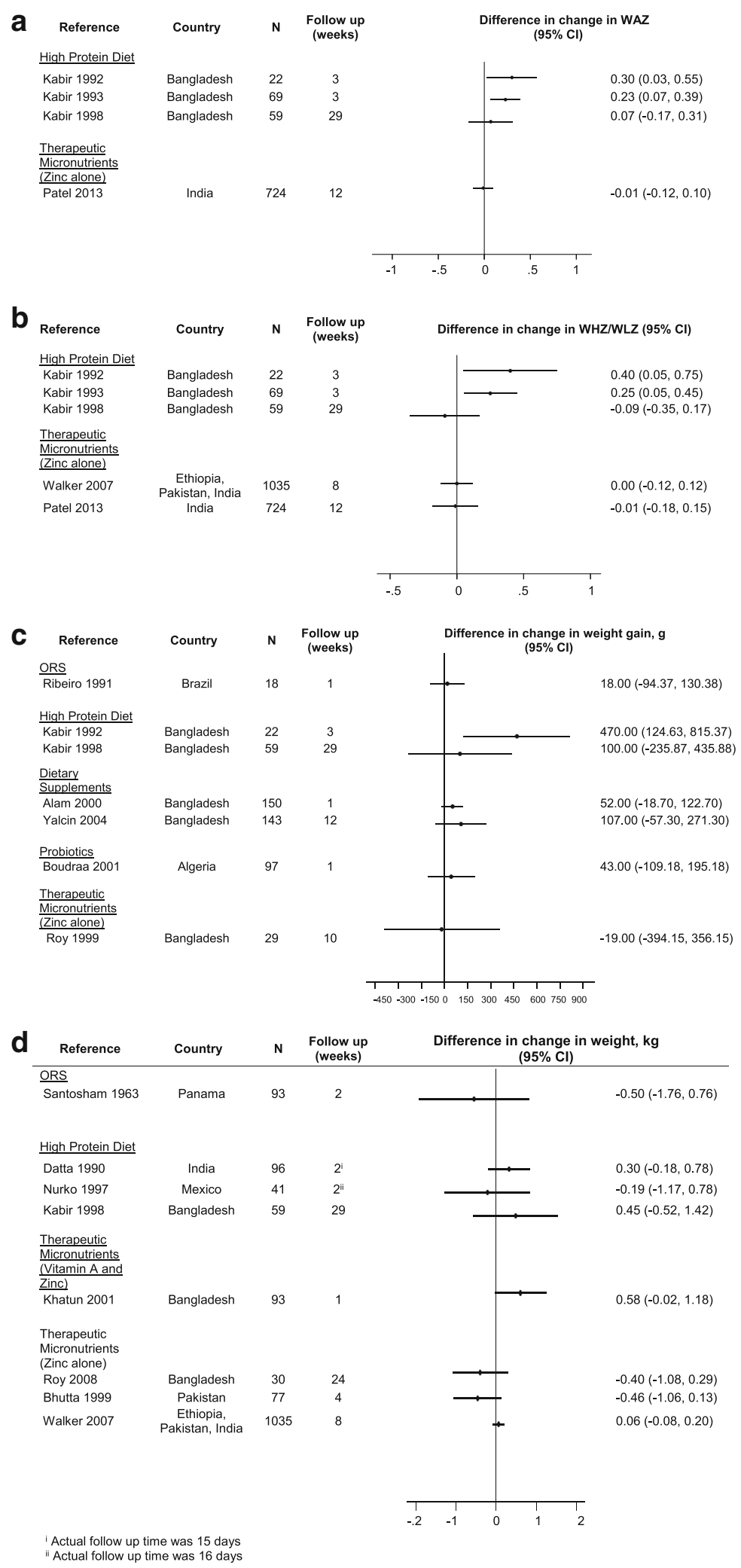

Fig. 4 (See legend on next page.) 
(See figure on previous page.)

Fig. 4 a Effect of diarrhea management interventions on change in WAZ (difference in change in WAZ and 95\% confidence interval). $\mathbf{b}$ Effect of diarrhea management interventions on change in WHZ/WLZ (difference in change in WHZ/WLZ and 95\% confidence interval). c Effect of diarrhea management interventions on weight gain (difference in weight gain [g] and 95\% confidence interval). $\mathbf{d}$ Effect of diarrhea management interventions on weight at follow up (difference in weight [kg] and 95\% confidence interval)

[51]. The single dietary fiber and probiotic trials evaluating weight gain did not find a significant effect [26, 47].

\section{Recurrent or prolonged diarrhea at follow-up}

Twenty studies (45.7\% of total) reported on diarrhea frequencies during follow-up periods ranging from 7 days to 3 months. The majority were trials of therapeutic zinc (13), including 2 that also assessed vitamin A, followed by probiotic trials (3), ORS formulation ( 3 comparisons in 2 trials) and 1 diet fiber and 1 lactose-free diet. Only 4 of the trials explicitly described being powered to address diarrhea prevalence or incidence during follow-up [22, 27, 31, 53]. Figure 5 shows the 12 trials (providing 15 estimates due to 3 trials including 3 arms) that reported data on prevalence of diarrhea 7 days or more after presentation $(8$ zinc $[2$ of which also assessed vitamin A], 2 ORS (1 of which compared 3 formulations), and 2 probiotic). Only 2 zinc studies $[22,31]$ and 1 probiotic (Saccharomyces boulardii) trial found a reduction in diarrhea prevalence associated with the intervention [41]. The other 6 zinc trials [23, 24, 32-34, 53] and probiotic trial of Lactobacillus rhamnosus GG [54] did not find a significant effect on diarrhea prevalence during follow-up. The lactose-free diet reported no effect on the presence of diarrhea at day $12(p=0.76)$ but did not report specific prevalences [17]. The 2 trials assessing ORS formulations (providing 3 estimates) did not demonstrate a benefit $[34,55]$ nor did the 2 vitamin A trials $[22,34]$.

Of studies reporting on diarrhea frequency indicators other than prevalence of diarrhea at follow-up, findings were heterogeneous. One study found that children given a rice-based diet with green banana or pectin (dietary fiber) were more likely to have recovered from diarrhea by day 5 of follow-up, while most children given the rice-based diet alone continued to have diarrhea until day 10 of follow-up [15]. Another found no children treated with Lactobacillus reuteri 17938 to have diarrhea beyond 7-days whereas $17.4 \%$ of children without probiotic treatment did have prolonged diarrhea [52]. A trial of 8070 community-based children found that those given zinc with ORS had 2.9 fewer episodes of diarrhea per 100 child-years (95\%CI: 0.8, 5.1) than those given ORS alone [27]. A study contrasting 10 day therapeutic zinc ( $20 \mathrm{mg} /$ day) with 3 months of supplemental zinc $(10 \mathrm{mg} /$ day) to the therapeutic zinc course alone found that the long term zinc reduced diarrhea incidence over a 9 month period by $21 \%$ (2.05 vs.2.59 episodes / child years) [30]. Compared to children given the multivitamin alone, children given a multivitamin with zinc had an average of 0.33 fewer subsequent diarrhea episodes (95\%

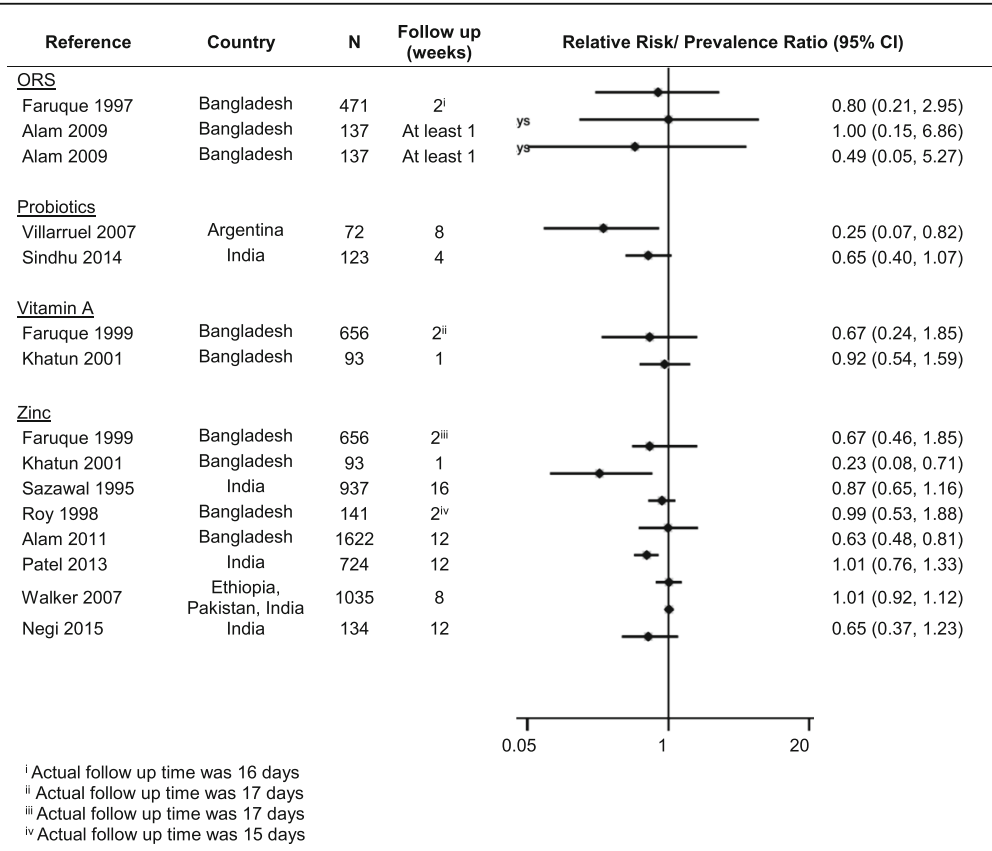

Fig. 5 Effect of diarrhea management interventions on diarrhea morbidity during follow up (relative risk or prevalence ratio of diarrhea at specified time during follow up [95\% CI]) 
CI: $-0.39,-0.27)$ and diarrhea incidence was similarly reduced in the 6 month follow-up period [28, 29]. Conversely, a placebo-controlled trial of therapeutic zinc among 1042 children reported no difference in the mean number of subsequent diarrhea episodes during a 3 month follow-up period nor did 2 smaller zinc trials [29, 32, 48].

\section{Discussion}

While significant progress has been made over the past 25 years in reducing deaths attributed to diarrhea, there is increasing recognition that diarrhea is associated with mortality, subsequent morbidities, and malnutrition in the period after a diarrheal episode $[56,57]$. These postacute sequelae highlight the need, and opportunity, to identify interventions to reduce morbidity and mortality among children presenting with diarrhea. This systematic review appraised diarrhea intervention trials for evidence of effects on post-acute sequelae of diarrhea, including mortality, nutritional status, and diarrhea presence during an extended follow-up period.

We found very few trials that evaluated post-acute diarrheal mortality, and only 1 (of zinc) was explicitly powered to address mortality and found mortality benefit [27]. The other zinc trials did not report a mortality benefit. As summarized in a recent Cochrane review, zinc appears to reduce diarrhea duration, particularly in malnourished children, although the degree to which this effect translates to mortality benefit remains unknown [58]. Therapeutic zinc also appears to have limited to no efficacy on morbidity or growth in children under 6 months of age $[53,59]$.

Post-acute mortality was assessed in 2 trials of antibiotics that found no mortality benefit, yet were underpowered to do so. Both trials included less than 100 children and only 1 was placebo-controlled. The role of antibiotics in diarrhea management remains controversial. In the absence of diagnostics, diarrhea management guidelines recommend antibiotics only for dysentery or suspected cholera [60,61]. Limiting antibiotics to these 2 indications may miss other serious enteric infections amenable to antibiotics [62, 63]. In practice however, many children without these indications are treated with an antibiotic, the benefits of which are not well understood [64]. Large placebo-controlled clinical trials are needed to determine the potential harm and/or benefit of antibiotics to reduce post-acute diarrhea morbidity and mortality.

Over 30 trials reported on growth outcomes. Dietary supplementation with macro- or micro-nutrients, high protein and lactose-free diets, and probiotics were assessed for effects on growth with mixed results. We found substantial variability in how growth outcomes were evaluated, making comparisons between studies challenging. Two of the 5 trials of dietary interventions found beneficial impacts on WAZ/WHZ with a high protein isocaloric diet. In a single study, glutamine demonstrated a signal of benefit at 1 time point which was not sustained. Most trials that assessed weight reported no intervention effect; perhaps because weight gain restored through hydration during the acute phase of diarrhea overshadowed weight gain from trialed interventions. High protein diets, either alone or in combination with micronutrients such as zinc, had a modest impact on short to medium term linear growth (3 weeks to 9 months). However, this effect was inconsistently demonstrated. High protein diets may restore the protein loss that can occur during and immediately after infection $[65,66]$. Replacing protein may modify growth consequences of diarrhea by increasing protein availability or by influencing hormonal regulation [67-69]. The combination of high protein and zinc may restore integrity of damaged mucosal surfaces and improve nutrient absorption [70-72]. However evidence around the effect of zinc on markers of intestinal permeability, as measured by the lactulose to mannitol ratio, are inconsistent $[49,73,74]$. Specific amino acids may also be important; glutamine has been shown to protect against bacterial translocation through maintenance of the gut barrier in animal models [75-77].

Diarrhea during follow-up was the most commonly reported outcome assessed in this review. Numerous systematic reviews of therapeutic zinc on diarrheal outcomes have been conducted, all of which suggest some benefit $[58,78-80]$. The effects of zinc on diarrhea at a specified day of follow-up were recently summarized in a Cochrane review and pooled relative risks of diarrhea at day 3 , day 5 , and day 7 associated with zinc all showed a statistically significant benefit [58]. Our review included diarrhea assessed at 7 days and beyond ( 7 days to 4 months) and found inconsistent results, perhaps demonstrating a waning in effect or sub-optimal statistical power at longer follow-up time points. Given therapeutic zinc is recommended for 14 days in current WHO management guidelines yet the data on benefit seems most pronounced within the first 7 days, days $7-$ 14 of the currently recommended zinc course may need further evaluation.

Three of the 4 probiotic trials evaluating diarrhea outcomes demonstrated a benefit on diarrhea during followup (Saccharomyces boulardii, Lactobacillus reuteri 17938 and 1 of the 2 Lactobacillus rhamnosus GG trials). However the Lactobacillus rhamnosus GG trial that did not find a benefit in diarrhea during follow-up did report improvements in intestinal function (as measured by the lactulose to mannitol test) and higher immunoglobulin $\mathrm{G}(\operatorname{IgG})$ in the subgroup of children with rotavirus infection treated with the probiotic [54]. Most clinical trials of probiotics have been conducted in high-resource settings and have treated and followed children for less than 7 days [81, 82]. Although not included in this review because it was published after the search was conducted, a recent pilot 
study ( $\mathrm{n}=76)$ conducted in Botswana found a greater increase in HAZ and reduced diarrhea recurrence over 60days of follow-up among admitted children with diarrhea randomized to Lactobacillus reuteri 17938, [62]. The European Society for Pediatric Gastroenterology recently recommended probiotics, specifically Saccharomyces boulardii or Lactobacillus rhamnosus GG, to reduce the duration and intensity of gastroenteritis [83]. The mechanisms by which probiotics may decrease diarrheal symptoms are largely unknown, but may act by out-competing pathogenic enteric infections for nutrients, restoring gut barrier functions, and/or by restoring gut microbial balance.

This review had several limitations. Most trials, particularly trials used to evaluate mortality, were underpowered. A 2 -armed clinical trial powered to detect a $50 \%$ reduction in a 3-month diarrheal case fatality rate of $2 \%$ would require over 4000 participants, a sample size far larger than most trials reporting mortality outcomes in this review and far smaller than sample sizes required to detect smaller intervention effects or lower case fatality rates. Many trials were excluded because of short length of follow-up and included trials had follow-up times ranging from 7-days to 9 months which could explain heterogeneity between studies, particularly studies of growth outcomes. Some interventions were more represented than others based on available clinical trial data. Markers of enteric function were not included in this review as prespecified outcomes, despite a growing body of evidence suggesting that enteric dysfunction is linked to poor outcomes following acute illness [84]. Because of the heterogeneity in interventions, outcome measurements, and follow-up time, we did not calculate pooled measures of effect. For the same reason, we did not report a GRADE score for every individual result but rather for overall study quality, and most trials were graded as low or very low. Standardized measures of the nutritional consequences of diarrhea and diarrhea morbidity will be important to enable future meta-analyses. This review includes data from a wide range of geographic, demographic and epidemiologic settings. However, most included trials were conducted in Asia, with less than 15\% of all included trials conducted in sub-Saharan Africa (SSA). Diarrhea-mortality rates are higher in SSA than in South Asia and recent projections of childhood mortality into 2030 predict that SSA will contribute to $60 \%$ of all childhood deaths $[5,57]$. Host characteristics, such as nutritional status and HIV-infection/-exposure vary greatly between these regions making generalizability of intervention effect challenging [85-87].

\section{Conclusions}

In many resource-limited settings, diarrheal episodes in young children are frequent and are associated with increased risk of mortality as well as growth failure and risk of subsequent infections. The mechanisms by which diarrhea and underlying enteric infections lead to morbidity, malnutrition, and mortality are multifactorial, likely requiring multiple complementary interventions to reduce likelihood of recurrence or persistence, promote healing of the gut mucosa, and to replenish lost protein and nutrients. Well-designed, multi-factorial, clinical trials evaluating the extended impact of diarrhea management interventions are urgently needed to reduce the long-term risks associated with diarrhea.

\section{Additional file}

Additional file 1: Supplement. (DOCX 129 kb)

\section{Abbreviations}

Cl: Confidence Interval; GRADE: Grading of Recommendations Assessment Development and Evaluation; HAZ: Height-for-age z-score; LAZ: Length-forage z-score; LMICs: Low- and middle-income countries; MSD: Moderate-tosevere diarrhea; MUAC: Mid upper arm circumference; PR: Prevalence Ratio; RCT: Randomized controlled trial; RR: Relative Risk; RUTF: Ready-to-use therapeutic foods; WAZ: Weight-for-age z-score; WHZ: Weight-for-height zscore; WLZ: Weight-for-length z-score

\section{Acknowledgements}

We would like to thank the Global Center for Integrated Health of Women, Adolescents, and Children, the Kenya Research and Training Center, and the Center for AIDS Research Enterics Working group for their support during the preparation of this article.

\section{Funding}

Funding was provided by the Bill and Melinda Gates Foundation (OPP1132140) and the UW Global Center for Integrated Health of Women, Adolescents and Children (Global WACh). JLW and DMD are supported by the Childhood Acute IIIness and Nutrition Network (CHAIN, OPP1131320). GJS is supported by a National Institute of Health mentoring award (grant number K24- HD054314) and PBP and GJS are supported by the International Core of the University of Washington Center for AIDS Research (CFAR; Seattle, WA, USA), an NIH funded program (P30 Al027757). The funders had no role in the study design, data abstraction, data interpretation, or writing of the manuscript.

\section{Availability of data and materials}

All data generated or analyzed during this study are included in this published article.

\section{Authors' contributions}

PBP, JLW, DMD, and GJS conceived of the idea and developed the protocol for this review. All titles and abstracts were screened by PBP and HEA, RLB and HEA reviewed all abstracts and full text articles with final input from PBP. RLB and HEA abstracted data from, and conducted GRADE assessments of, included studies. All authors contributed to the development, reading, and approving the final version for publication.

Ethics approval and consent to participate

Not applicable

Consent for publication

Not applicable

Competing interests

The authors declare that they have no competing interests. 


\section{Publisher's Note}

Springer Nature remains neutral with regard to jurisdictional claims in published maps and institutional affiliations.

\section{Author details}

${ }^{1}$ Department of Global Health, University of Washington, Seattle, WA, USA. ${ }^{2}$ Department of Epidemiology, University of Washington, Seattle, WA, USA. ${ }^{3}$ Department of Pediatrics, University of Washington, Seattle, WA, USA. ${ }^{4}$ Department of Medicine (Infectious Disease), University of Washington, Seattle, WA, USA. ${ }^{5}$ Department of Health Services, University of Washington, Seattle, WA, USA.

Received: 7 August 2017 Accepted: 17 January 2018 Published online: 01 February 2018

\section{References}

1. Liu L, Oza S, Hogan D, Chu Y, Perin J, Zhu J, Lawn JE, Cousens S, Mathers C, Black RE. Global, regional, and national causes of under-5 mortality in 200015: an updated systematic analysis with implications for the sustainable development goals. Lancet. 2016;388(10063):3027-35.

2. Kotloff KL, Nataro JP, Blackwelder WC, Nasrin D, Farag TH, Panchalingam S, Wu Y, Sow SO, Sur D, Breiman RF, et al. Burden and aetiology of diarrhoea disease in infants and young children in developing countries (the global enteric multicenter study, GEMS): a prospective, case-control study. Lancet. 2013;382:209-22

3. Rahman AE, Molla M, Worku A, Hurt L, Kirkwood B, Mohan B, Bhutta Z, Raza F, Mrema S. Childhood diarrhoeal deaths in seven low- and middle-income countries. Bull World Health Organ. 2014;92:664-71.

4. Checkley W, Buckley G, Gilman RH, Assis AM, Guerrant RL, Morris SS, Mølbak K, Valentiner-Branth P, Lanata CF, Black RE. Multi-country analysis of the effects of diarrhoea on childhood stunting. Int J Epidemiol. 2008;37:816-30.

5. Liu L, Johnson H, Cousens S. Global, regional, and national causes of child mortality in 2000-2010: an updated systematic analysis. Lancet. 2015;385: 430-40.

6. Black RE, Victora CG, Walker SP, Bhutta ZA, Christian P, de Onis M, Ezzati M, Grantham-McGregor S, Katz J, Martorell R, et al. Maternal and child undernutrition and overweight in low-income and middle-income countries. Lancet. 2013;382(9890):427-51.

7. World Bank Group. Low \& Middle Income Countries. World Bank. 2016 https://datahelpdesk.worldbank.org/knowledgebase/articles/906519-worldbank-country-and-lending-groups.

8. Gilman R, Koster F, Islam S, McLaughlin J, Rahaman M. High- and low-dose Ampicillin therapy for treatment of severe dysentery due to Shigella dysenteriae type 1. Antimicrob Agents Chemother. 1980;17:402-5.

9. Datta D, Datta P, Bhattacharya SK, Mitra U, Bhattacharya MK, Sen D, Sinha AK, Manna B, Mitra AK, Lahiri M, et al. Effect of protein rich diet during acute phase of dysentery. Indian J Public Health. 1990;34:1-5.

10. Kabir I, Butler T, Underwood LE, Rahman MM. Effects of a protein-rich diet during convalescence from shigellosis on catch-up growth, serum proteins, and insulin-like growth factor-I. Pediatr Res. 1992;32:689-92.

11. Kabir I, Malek M, Mazumder RN, Rahman M, Mahalanabis D. Rapid during growth of children fed a high-protein convalescence from shigellosis13. Am J Clin Nutr. 1993:57:441-5.

12. Mazumder RN, Hoque SS, Ashraf H, Kabir I, Wahed MA. Early feeding of an energy dense diet during acute shigellosis enhances growth in malnourished children. J Nutr. 1997:127:51-4.

13. Kabir I, Rahman MM, Haider R, Mazumder RN, Khaled MA, Mahalanabis D. Increased height gain of children fed a high-protein diet during convalescence from shigellosis: a six-month follow-up study. J Nutr. 1998; 128:1688-91.

14. Mazumder RN, Ashraf H, Hoque SS, Kabir I, Majid N, Wahed MA, Fuchs GJ, Mahalanabis D: Effect of an energy-dense diet on the clinical course of acute shigellosis in undernourished children. Br J Nutr 2000, 84:775-779.

15. Rabbani GH, Teka T, Zaman B, Majid N, Khatun M, Fuchs GJ. Clinical studies in persistent diarrhea: dietary management with green banana or pectin in Bangladeshi children. Gastroenterology. 2001;121:554-60.

16. Bhan MK, Arora NK, Khoshoo PR, Bhatnagar S, Sazawal S, Sharma K. Comparison of a lactose-free cereal-based formula and cow's milk in infants and children with acute gastroenteritis. J Pediatr Gastroenterol Nutr. 1988;7:208-13.
17. Bhatnagar S, Bhan M, Singh K, Saxena S, Shariff M. Efficacy of milk-based diets in persistent diarrhea- a randomized, controlled trial. Pediatrics. 1996;98

18. Alam NH, Islam S, Sattar S, Monira S, Desjeux J-F. Safety of rapid intravenous rehydration and comparative efficacy of 3 oral rehydration solutions in the treatment of severely malnourished children with dehydrating cholera. J Pediatr Gastroenterol Nutr. 2009:48:318-27.

19. Misra S, Sabui T, Pal N. A randomized controlled trial to evaluate the efficacy of lactobacillus GG in infantile diarrhea. J Pediatr. 2009;155:129-32.

20. Sindhu KN, Sowmyanarayanan TV, Paul A, Babji S, Ajjampur SS, Priyadarshini S, Sarkar R, Balasubramanian KA, Wanke CA, Ward HD, et al. Immune response and intestinal permeability in children with acute gastroenteritis treated with lactobacillus rhamnosus GG: a randomized, double-blind, placebo-controlled trial. Clin Infect Dis. 2014:58(8):1107-15.

21. Faruque AS, Hoque SS, Fuchs GJ, Mahalanabis D. Randomized, controlled, clinical trial of rice versus glucose oral rehydration solutions in infants and young children with acute watery diarrhoea. Acta Paediatr. 1997;86:1308-11.

22. Khatun UH, Malek MA, Black RE, Sarkar NR, Wahed MA, Fuchs G, Roy SK. A randomized controlled clinical trial of zinc, vitamin a or both in undernourished children with persistent diarrhea in Bangladesh. Acta Paediatr. 2001;90:376-80.

23. Sazawal S, Black RE, Bhan MK, Bhandari N, Sinha A, Jalla S. Zinc supplementation in young children with acute diarrhea in India. N Engl J Med. 1995;333:839-44.

24. Roy SK, Tomkins AM, Mahalanabis D, Akramuzzaman SM, Haider R, Behrens $\mathrm{RH}$, Fuchs $\mathrm{G}$. Impact of zinc supplementation on persistent diarrhoea in malnourished Bangladeshi children. Acta Paediatr. 1998;87:1235-9.

25. Roy SK, Behrens RH, Haider R, Akramuzzaman SM, Mahalanabis D, Wahed MA, Tomkins AM. Impact of zinc supplementation on intestinal permeability in Bangladeshi children with acute diarrhoea and persistent diarrhoea syndrome. J Pediatr Gastroenterol Nutr. 1999;15:289-96.

26. Alam NH, Meier R, Schneider H, Sarker SA, Bardhan PK, Mahalanabis D, Fuchs GJ, Gyr N. Partially hydrolyzed guar gum-supplemented oral rehydration solution in the treatment of acute diarrhea in children. J Pediatr Gastroenterol Nutr. 2000;31:503-7.

27. Baqui AH, Black RE, El Arifeen S, Yunus M, Chakraborty J, Ahmed S, Vaughan JP. Effect of zinc supplementation started during diarrhoea on morbidity and mortality in Bangladeshi children: community randomised trial. BMJ. 2002;325(7372):1059.

28. Roy SK, Tomkins AM, Haider R, Behren RH, Akramuzzaman SM, Mahalanabis D, Fuchs GJ. Impact of zinc supplementation on subsequent growth and morbidity in Bangladeshi children with acute diarrhoea. Eur J Clin Nutr. 2007:53:529-34

29. Roy SK, Raqib R, Khatun W, Azim T, Chowdhury R, Fuchs GJ, Sack DA. Zinc supplementation in the management of shigellosis in malnourished children in Bangladesh. Eur J Clin Nutr. 2008;62:849-55.

30. Larson CP, Nasrin D, Saha A, Chowdhury MI, Qadri F. The added benefit of zinc supplementation after zinc treatment of acute childhood diarrhoea: a randomized, double-blind field trial. Trop Med Int Health. 2010;15:754-61.

31. Alam DS, Yunus $M$, El Arifeen $S$, Chowdury HR, Larson CP, Sack DA, Baqui $\mathrm{AH}$, Black RE. Zinc treatment for 5 or 10 days is equally efficacious in preventing diarrhea in the subsequent 3 months among Bangladeshi children. J Nutr. 2011:141:312-5.

32. Patel AB, Dibley MJ, Mamtani M, Badhoniya N, Kulkarni H. Therapeutic zinc and copper supplementation in acute diarrhea does not influence shortterm morbidity and growth: double-blind randomized controlled trial. Pediatr Infect Dis J. 2013:32(1):91-3.

33. Negi R, Dewan P, Shah D, Das S, Bhatnagar S, Gupta P. Oral zinc supplements are ineffective for treating acute dehydrating diarrhoea in 512-year-olds. Acta Paediatr. 2015;104(8):e367-71.

34. Faruque AS, Mahalanabis D, Haque SS, Fuchs GJ, Habte D. Double-blind, randomized, controlled trial of zinc or vitamin A supplementation in young children with acute diarrhoea. Acta Paediatr. 1999:88:154-60.

35. Eichenberger JR, Hadorn B, Schmidt B. A semi-elemental diet with low osmolarity and high content of hydrolyzed lactalbumin in the treatment of acute diarrhea in malnourished children. Arq Gastroenterol. 1984;21:130-5.

36. Nurko S, García-Aranda JA, Fishbein E, Pérez-Zúñiga MI. Successful use of a chicken-based diet for the treatment of severely malnourished children with persistent diarrhea: a prospective, randomized study. J Pediatr. 1997;131:405-12.

37. de Mattos Â, Ribeiro T, Mendes P, Valois S, Mendes C, Ribeiro H. Comparison of yogurt, soybean, casein, and amino acid-based diets in children with persistent diarrhea. Nutr Res. 2009;29:462-9. 
38. Lozano J, Cespedes J. Lactose vs lactose free regimen in children with acute diarrhoae: a randomized controlled trial. Arch Latinoam Nutr. 1994;44

39. Santosham M, Carrera E, Sack RB. Oral rehydration therapy in well nourished ambulatory children. Am J Trop Med Hyg. 1983:32:804-8.

40. Ribeiro HCJ, Lifshitz F. Alanine-based oral rehydration therapy for infants with acute diarrhea. Pediatrics. 1991;118:S86-90.

41. Villarruel G, Rubio DM, Lopez F, Cintioni J, Gurevech R, Romero G, Vandenplas Y. Saccharomyces boulardii in acute childhood diarrhoea: a randomized, placebo-controlled study. Acta Paediatr. 2007;96:538-41.

42. Amadi B, Mwiya M, Musuku J, Watuka A, Sianongo S, Ayoub A, Kelly P. Effect of nitazoxanide on morbidity and mortality in Zambian children with cryptosporidiosis: a randomised controlled trial. Lancet. 2002;360:1375-80.

43. Valentiner-Branth P, Steinsland H, Santos G, Perch M, Begtrup K, Bhan MK, Dias F, Aaby P, Sommerfelt H, Mølbak K. Community-based controlled trial of dietary management of children with persistent diarrhea: sustained beneficial effect on ponderal and linear growth. Am J Clin Nutr. 2001;73:968-74.

44. Rollins NC, Van Den Broeck J, Kindra G, Pent M, Kasambira T, Bennish ML. The effect of nutritional support on weight gain of HIV-infected children with prolonged diarrhoea. Acta Paediatr. 2007;96:62-8.

45. van der Kam S, Roll S, Swarthout T, Edyegu-Otelu G, Matsumoto A, Kasujja FX, Casademont C, Shanks L, Salse-Ubach N. Effect of short-term supplementation with ready-to-use therapeutic food or micronutrients for children after illness for prevention of malnutrition: a randomised controlled trial in Uganda. PLoS Med. 2016;13(2):e1001951.

46. van der Kam S, Salse-Ubach N, Roll S, Swarthout T, Gayton-Toyoshima S, Jiya NM, Matsumoto A, Shanks L. Effect of short-term supplementation with ready-to-use therapeutic food or micronutrients for children after illness for prevention of malnutrition: a randomised controlled trial in Nigeria. PLoS Med. 2016;13(2):e1001952.

47. Boudraa G, Benbouabdellah M, Hachelaf W, Boisset M, Desjeux JF, Touhami M. Effect of feeding yogurt versus milk in children with acute diarrhea and carbohydrate malabsorption. J Pediatr Gastroenterol Nutr. 2001;33(3):307-13.

48. Fajolu I, Emokpae A, Oduwole A, Silva B, Abidoye R, Renner J. Zinc supplementation in children with acute diarrhoea. Nig. Q. J. Hosp. Med. 2008;18:101-3.

49. Bhutta Z, Nizami SQ, Isani Z. Zinc supplementation in malnourished children with persistent diarrhea in Pakistan. Pediatrics. 1999;103

50. Bhutta Z, Molla A, Badruddin S. Dietary management of persistent diarrheacomparison of a traditional rice-lentil based diet with soy formula. Pediatrics. 1991;88:1010-8.

51. Yalçin SS, Yurdakök K, Tezcan I, Oner L. Effect of glutamine supplementation on diarrhea, interleukin-8 and secretory immunoglobulin a in children with acute diarrhea. J Pediatr Gastroenterol Nutr. 2004:38:494-501.

52. Dinleyici EC, Vandenplas Y. Lactobacillus reuteri DSM 17938 effectively reduces the duration of acute diarrhoea in hospitalised children. Acta Paediatr. 2014;103:300-5

53. Walker CL, Bhutta ZA, Bhandari N, Teka T, Shahid F, Taneja S, Black RE, Rasool S, Nizami SQ, Rongsen T, et al. Zinc during and in convalescence from diarrhea has no demonstrable effect on subsequent morbidity and anthropometric status among infants $<6$ mo of age. Am J Clin Nutr. 2007;85:887-94.

54. Sindhu KNC, Sowmyanarayanan TV, Paul A, Babji S, Ajjampur SSR, Priyadarshini S, Sarkar R, Balasubramanian KA, Wanke CA, Ward HD, et al. Immune response and intestinal permeability in children with acute gastroenteritis treated with lactobacillus rhamnosus GG: A randomized, double-blind, placebo-controlled trial. Clin Infect Dis. 2014;58:1107-15.

55. Alam S, Mushtaq M. Antibiotic associated diarrhea in children. Indian Pediatr. 2009:46(6):491-6

56. Liu L, Oza S, Hogan D, Perin J, Rudan I, Lawn JE, Cousens S, Mathers C, Black RE. Global, regional, and national causes of child mortality in 2000-13, with projections to inform post-2015 priorities: an updated systematic analysis. Lancet. 2014;

57. Kotloff KL, Nataro JP, Blackwelder WC, Nasrin D, Farag TH, Panchalingam S, Wu Y, Sow SO, Sur D, Breiman RF, et al. Burden and aetiology of diarrhoea disease in infants and young children in developing countries (the global enteric multicenter study, GEMS): a prospective, case-control study. Lancet. 2013;382(9888):209-22.

58. Lazzerini M, Wanzira H. Oral zinc for treating diarrhoea in children. Cochrane Database Syst Rev. 2016;12:CD005436.
59. Fischer Walker CL, Bhutta ZA, Bhandari N, Teka T, Shahid F, Taneja S, Black RE, Zinc Study G. Zinc supplementation for the treatment of diarrhea in infants in Pakistan, India and Ethiopia. J Pediatr Gastroenterol Nutr. 2006;43(3):357-63.

60. Organization WH: Pocket book of hospital care for children: guidelines for the management of common illnesses second edition. In. Geneva, Switzerland: WHO; 2013.

61. Organization WH: Diarrhoea Treatment Guidelines. In. Geneva, Switzerland: WHO; 2005

62. PPernica JM, Steenhoff AP, Mokomane M, et al. Rapid enteric testing to permit targeted antimicrobial therapy, with and without Lactobacillus reuteri probiotics, for paediatric acute diarrhoeal disease in Botswana: A pilot, randomized, factorial, controlled trial. PLoS One. 2017;12:e0185177.

63. Pavlinac PB, Denno DM, John-Stewart GC, Onchiri FM, Naulikha JM, Odundo EA, Hulseberg CE, Singa BO, Manhart LE, Walson JL. Failure of SyndromeBased Diarrhea Management Guidelines to Detect Shigella Infections in Kenyan Children. J Pediatric Infect Dis Soc. 2016;(5, 4):366-74.

64. Rogawski ET, Platts-Mills JA, Seidman JC, John S, Mahfuz M, Ulak M, Shrestha SK, Soofi SB, Yori PP, Mduma E, et al. Use of antibiotics in children younger than two years in eight countries: a prospective cohort study. Bull World Health Organ. 2017;95(1):49-61.

65. Weizman Z, Binsztok M, Fraser D, Deckelbaum RJ, Granot E. Intestinal protein loss in acute and persistent diarrhea of early childhood. J Clin Gastroenterol. 2002;34(4):427-9.

66. Sarker SA, Wahed MA, Rahaman MM, Alam AN, Islam A, Jahan F. Persistent protein losing enteropathy in post measles diarrhoea. Arch Dis Child. 1986; 61(8):739-43.

67. Lutter CK, Mora JO, Habicht JP, Rasmussen KM, Robson DS, Sellers SG, Super CM, Herrera MG. Nutritional supplementation: effects on child stunting because of diarrhea. Am J Clin Nutr. 1989;50(1):1-8.

68. Gat-Yablonski G, Phillip M. Nutritionally-induced catch-up growth. Nutrients. 2015;7(1):517-51.

69. Soliman AT, ElZalabany MM, Salama M, Ansari BM. Serum leptin concentrations during severe protein-energy malnutrition: correlation with growth parameters and endocrine function. Metab Clin Exp. 2000;49(7):819-25.

70. Chouraqui JP, Michard-Lenoir AP. Feeding infants and young children with acute diarrhea. Arch Pediatr. 2007;14(Suppl 3):S176-80.

71. Berni Canani R, Buccigrossi V, Passariello A. Mechanisms of action of zinc in acute diarrhea. Curr Opin Gastroenterol. 2011;27(1):8-12.

72. Bettger WJ, O'Dell BL. A critical physiological role of zinc in the structure and function of biomembranes. Life Sci. 1981;28(13):1425-38.

73. Alam AN, Sarker SA, Wahed MA, Khatun M, Rahaman MM. Enteric protein loss and intestinal permeability changes in children during acute shigellosis and after recovery: effect of zinc supplementation. Gut. 1994;35(12):1707-11.

74. Tran CD, Hawkes J, Graham RD, Kitchen JL, Symonds EL, Davidson GP Butler RN. Zinc-fortified oral rehydration solution improved intestinal permeability and small intestinal mucosal recovery. Clin Pediatr (Phila). 2015;54(7):676-82.

75. Alverdy JA, Aoys E, Weiss-Carrington P, Burke DA. The effect of glutamineenriched TPN on gut immune cellularity. J Surg Res. 1992;52(1):34-8.

76. Barber AE, Jones WG 2nd, Minei JP, Fahey TJ 3rd, Moldawer LL, Rayburn JL, Fischer E, Keogh CV, Shires GT, Lowry SF. Harry M. Vars award. Glutamine or fiber supplementation of a defined formula diet: impact on bacterial translocation, tissue composition, and response to endotoxin. JPEN J Parenter Enteral Nutr. 1990;14(4):335-43.

77. Burke DJ, Alverdy JC, Aoys E, Moss GS. Glutamine-supplemented total parenteral nutrition improves gut immune function. Arch Surg. 1989; 124(12):1396-9.

78. Galvao TF, Thees MF, Pontes RF, Silva MT, Pereira MG. Zinc supplementation for treating diarrhea in children: a systematic review and meta-analysis. Rev Panam Salud Publica. 2013;33(5):370-7.

79. Lamberti LM, Walker CL, Chan KY, Jian WY, Black RE. Oral zinc supplementation for the treatment of acute diarrhea in children: a systematic review and meta-analysis. Nutrients. 2013;5(11):4715-40.

80. Walker $\mathrm{CL}$, Black RE. Zinc for the treatment of diarrhoea: effect on diarrhoea morbidity, mortality and incidence of future episodes. Int J Epidemiol. 2010; 39(Suppl 1):i63-9.

81. Allen SJ, Martinez EG, Gregorio GV, Dans LF. Probiotics for treating acute infectious diarrhoea. Cochrane Database Syst Rev. 2010;11:CD003048.

82. Applegate JA, Fischer Walker CL, Ambikapathi R, Black RE. Systematic review of probiotics for the treatment of community-acquired acute diarrhea in children. BMC Public Health. 2013;13(Suppl 3):S16. 
83. Guarino A, Ashkenazi S, Gendrel D, Lo Vecchio A, Shamir R, Szajewska H. European Society for Pediatric Gastroenterology, Hepatology, and nutrition/ European Society for Pediatric Infectious Diseases evidence-based guidelines for the management of acute gastroenteritis in children in Europe: update 2014. J Pediatr Gastroenterol Nutr. 2014;59(1):132-52.

84. Denno DM, VanBuskirk KM, Nelson ZC, Musser CA, Tarr PI.: Environmental enteric dysfunction: advancing current knowledge. St. Louis, MO: Washington University Libraries; 2016.

85. Collaborators GH, Wang H, Wolock TM, Carter A, Nguyen G, Kyu HH, Gakidou E, Hay SI, Mills EJ, Trickey A, et al. Estimates of global, regional, and national incidence, prevalence, and mortality of HIV, 1980-2015: the global burden of disease study 2015. Lancet HIV. 2016;3(8):e361-87.

86. Pavlinac PB, John-Stewart GC, Naulikha JM, Onchiri FM, Denno DM, Odundo EA, Singa BO, Richardson BA, Walson JL. High-risk enteric pathogens associated with HIV infection and HIV exposure in Kenyan children with acute diarrhoea. AIDS. 2014;28(15):2287-96.

87. Mondal D, Haque R, Sack RB, Kirkpatrick BD, Petri WA Jr. Attribution of malnutrition to cause-specific diarrheal illness: evidence from a prospective study of preschool children in Mirpur, Dhaka, Bangladesh. Am J Trop Med Hyg. 2009;80(5):824-6.

\section{Submit your next manuscript to BioMed Central} and we will help you at every step:

- We accept pre-submission inquiries

- Our selector tool helps you to find the most relevant journal

- We provide round the clock customer support

- Convenient online submission

- Thorough peer review

- Inclusion in PubMed and all major indexing services

- Maximum visibility for your research

Submit your manuscript at www.biomedcentral.com/submit 